\title{
LAS COMPETENCIAS DE LA COMISIÓN NACIONAL DE LOS MERCADOS Y DE LA COMPETENCIA Y LAS AUTORIDADES AUTONÓMICAS EN LA APLICACIÓN DEL DERECHO DE LA COMPETENCIA
}

\author{
Javier Guillén Caramés
}

SUMARIO: 1. INTRODUCCIÓN 2. LA ORGANIZACIÓN ADMINISTRATIVA DEL DERECHO DE LA COMPETENCIA: LA CREACIÓN DE AUTORIDADES AUTONÓMICAS DE LA COMPETENCIA 2.1. La fase inicial: la configuración desigual del modelo de autoridad autonómica de competencia 2.2. La Ley 15/2007 de Defensa de la Competencia y su incidencia en la progresiva equiparación del modelo de autoridad de competencia 3. LA APLICACIÓN DESCENTRALIZADA DEL DERECHO DE LA COMPETENCIA 3.1. La necesidad de garantizar la coordinación en la aplicación del Derecho de la Competencia: criterios empleados por la Ley 1/2002 3.1.1. Los puntos de conexión: la necesidad de una precisa delimitación de los mismos. 3.1.2. Criterios previstos por la Ley 1/2002 para delimitar cuando u na conducta altera la libre competencia en un ámbito supraautonómico o en el conjunto del mercado nacional. 3.1.3. Criterios conectados directamente con el principio de unidad de mercado para delimitar cuando una conducta altera la libre competencia en un ambito supraautonomico o en el conjunto del mercado nacional. 3.2. Consecuencias jurídicas derivadas del alto grado de complejidad en la determinación de los criterios establecidos en la Ley 1/2002: la posible conflictividad 3.3. Ambitos de la ejecución del Derecho de la Competencia atribuidos en exclusiva al Estado 3.4. El problema del procedimiento de control de concentraciones empresariales: ¿posible invasión del ámbito competencial autonómico? 3.5. Ambitos de la ejecución del Derecho de la Competencia atribuidos a las Comunidades Autónomas 3.5.1. La actividad de defensa de la 
competencia 3.5.2. La actividad de promoción de la competencia: una nueva forma de actividad administrativa en el Derecho de la Competencia A) Delimitación de la actividad de promoción de la competencia B) Encuadre jurídico de la actividad de promoción: el empleo del soft law en el Derecho de la Competencia C) La regulación económica mediante técnicas de soft law: sus efectos jurídicos. Límites a la actividad de promoción de la competencia autonómica.

\section{INTRODUCCIÓN}

La sentencia del Tribunal Constitucional 208/1999, de 11 de noviembre de 1999, dictada con motivos de los recursos de inconstitucionalidad interpuestos por los representantes del Gobierno vasco y catalán, estimó en parte los mismos, declarando la inconstitucionalidad de la cláusula «en todo o en parte del mercado nacional» contenida expresamente o por remisión en diversos preceptos de la Ley 16/89, de Defensa de la Competencia ${ }^{1}$.

Como consecuencia del fallo, se generaron unos efectos concretos que se traducían en la necesidad de establecer, mediante Ley estatal, el marco normativo básico para el desarrollo de las competencias ejecutivas del Estado y las Comunidades Autónomas recogidas en la LDC 16/89 y en su desarrollo reglamentario. En este sentido, debe recordarse que la nulidad de los preceptos declarados inconstitucionales quedó diferida hasta el momento en que establecidos por Ley estatal los criterios de conexión pertinentes pudieran las Comunidades Autónomas ejercer las competencias que el Alto Tribunal les reconoció.

Debe traerse a colación del mismo modo, que el legislador -al que la STC 208/1999 sorprendió cuando, precisamente, se estaba discutiendo en el Senado un proyecto de Ley que venía a modificar la LDC 16/89- había optado por tomarse un periodo de reflexión y había introducido en la Ley que estaba tramitando -que terminó siendo la Ley 52/1999- una Disposición Final Segunda que permitía al Gobierno aplazar hasta el 1 de octubre del 2000 la presentación al Congreso de los Diputados del proyecto de ley necesario para la correcta ejecución de la sentencia.

Pues bien, la Ley 1/2002, de 21 de febrero, de coordinación de las competencias del Estado y de las Comunidades Autónomas en materia de defensa de la competencia, viene a cumplir esta función, si bien con un cierto retraso respecto a la fecha prevista en la Ley 52/1999, pues el proyecto de Ley no fue presentado ante el Congreso hasta el día 22 de junio de 2001, siendo calificado

1 Vid., sobre este tema, mi libro Libre competencia y Estado autonómico, Marcial Pons-URJC, Madrid 2006. 
por la Mesa el día 26 del mismo mes, por lo que prácticamente habían transcurrido casi dos años desde que tuvo lugar el pronunciamiento del $\mathrm{TC}^{2}$. Este hecho fue así denunciado por algunos grupos parlamentarios en los trámites de discusión de este proyecto de Ley, pero forzoso es reconocer, como advirtió tempranamente MARTINEZ LAGE, «que todos ellos parecían hacerlo «con la boca pequeña»: todos los grupos reconocían -además de los retrasos derivados del cambio de legislatura- la delicadeza y dificultad de este texto legislativo». Así, por ejemplo, el portavoz de Convergencia i Unió en la Comisión del Congreso que debatió el proyecto con competencia legislativa plena -se trataba de la Comisión de Economía y Hacienda-, afirmaba lo siguiente:

«hay que admitir que estamos ante un texto de difícil configuración y no ya por lo delicado de la materia (...) la dificultad (...) se debe sobre todo a la confluencia de tres niveles administrativos -competencias normativas y ejecutivas en el ámbito de la Unión Europea (...), competencias normativas y ejecutivas del Estado español y competencias ejecutivas de las Comunidades Autónomas» ${ }^{3}$

En efecto, recordando una vez más lo dispuesto por la STC 208/1999 que nunca cuestionó la competencia exclusiva del Estado para legislar sobre esta materia, sino que se limitó a reconocer a las Comunidades Autónomas su competencia en la ejecución de la LDC, siempre y cuando no afectara a la unidad del mercado, en cuyo caso esta competencia de ejecución correspondería al Estado. Por lo tanto, respecto a la Ley 1/2002, debe afirmarse que nos encontramos ante un texto legislativo difícil, delicado y aparentemente polémico, o al menos, engendrado bajo el signo de la complejidad, por los conceptos jurídicos indeterminados con los que se pretende delimitar la aplicación descentralizada del Derecho de la Competencia en España.

En definitiva, puede decirse que con la aprobación de la Ley 1/2002 se dio cumplimiento al mandato establecido por el TC en la ya citada sentencia y, por tanto, supuso la nulidad de los preceptos declarados inconstitucionales por ella, acabándose de esta forma la situación de transitoriedad que se derivaba del contenido del fallo constitucional. Debe advertirse, que el examen de los criterios establecidos por la Ley 1/2002 deben ser interpretados en el nuevo marco desarrollado por la Ley 15/2007, de 3 de julio, de Defensa de la Competencia (LDC) que modifica sustancialmente el sistema de aplicación pública de la normativa de competencia y que modifica parcialmente la Ley 1/2002. Así, el nuevo art. 13 LDC se refiere a los órganos competentes de las CCAA estableciendo que

${ }^{2}$ BOCG, Congreso de los Diputados, Serie A, núm. 40-1, de 29 de junio de 2001.

3 Diario de Sesiones del Congreso de los Diputados, Pleno, núm. 108, de 27 de septiembre de 2001, pág. 5226. 
1. Los órganos de las Comunidades Autónomas competentes para la aplicación de esta Ley ejercerán en su territorio las competencias ejecutivas correspondientes en los procedimientos que tengan por objeto las conductas previstas en los artículos 1, 2 y 3 de esta Ley de acuerdo con los dispuesto en la misma y en la Ley 1/2002, de 21 de febrero, de coordinación de las competencias del Estado y las Comunidades Autónomas en materia de Defensa de la Competencia 4 .

\section{LA ORGANIZACIÓN ADMINISTRATIVA DEL DERECHO DE LA COMPETENCIA}

Una de las consecuencias que derivaban del cumplimiento de la STC 208/1999, esto es, una vez el Estado estableciera los puntos de conexión y las medidas de coordinación necesarias para que la aplicación descentralizada del Derecho de la Competencia, era la creación de una organización específica por parte de aquellas CCAA que lo estimaran pertinente de cara a poder desarrollar sus competencias ejecutivas sobre este ámbito.

En este sentido, han sido varias las CCAA que han creado autoridades de defensa de la competencia, de distinta naturaleza, en sus respectivos ámbitos territoriales: Cataluña, Madrid, Galicia, País Vasco, Extremadura, Aragón, Castilla y León, Castilla-La Mancha, Valencia y Andalucía. El modelo y forma de organización de cada una de ellas ha sido desigual y, en consecuencia su funcionamiento y eficacia ha sido dispar ${ }^{5}$. En las siguien-

${ }^{4}$ Como señala Pareja, C., «En congruencia con dicha previsión, la Disposición Adicional Octava (...) establece expresamente que las referencias a las funciones, potestades y procedimientos de la $\mathrm{CNC}$ y sus órganos directivos se deberá entender efectuada a los órganos de competencia autonómicos cuando las dichas actuaciones de refieran a los supuestos en que el ejercicio de la competencia corresponda a dichos órganos autonómicos, conforme a los criterios de conexión establecidos en el artículo 1 de la Ley. Tal equiparación tienen un inevitable carácter genérico, a fin de no coincidir la capacidad autoorganizatoria de que disfrutan las Comunidades autónomas para la estructuración de sus propios órganos de defensa de la competencia»; a ello se añade que debe entenderse que la equiparación entre órganos estatales y autonómicos vienen a reemplazar a la previsión análoga contenida en la DA Primera de la Ley 1/2002, que dispuso asimismo dicha equiparación, aunque estableciéndola mediante una referencia a los artículos concretos de la LDC 16/89 que atribuían funciones a los órganos estatales que, en virtud de dicha Disposición, debía entenderse que eran susceptibles de ser ejercidas por parte de las autoridades autonómicas que se puedan crear; vid., «DA $8^{\mathrm{a}}$ », en Comentario a la LDC, Civitas-Thomson Reuters, Madrid 2012, págs.. 1156 y ss.

${ }^{5}$ Como acertadamente señala MARCos, F., «en la mayoría de las CCAA la creación de autoridades de defensa de la competencia no ha sido fruto de una reflexión previa sobre las flamantes competencias autonómicas en la materia, ni sobre el sentido de los nuevos órganos autonómicos y su necesidad y encaje en la realidad económica local», vid., «Au- 
tes líneas examinaré los modelos que han desplegado las autoridades autonómicas de competencia que se han creado, distinguiendo la evolución que han tenido las mismas en función de la legislación de competencia que han tenido y tienen que aplicar la cual fue objeto de un profundo cambio en el año 2007, lo que conllevó la implantación de un nuevo modelo de autoridad de competencia.

\subsection{La fase inicial: la configuración desigual del modelo de autoridad autonómica dirigida a la ejecución del Derecho de la Competencia}

En la fase inicial de creación de autoridades autonómicas de competencia puede afirmarse, en primer lugar, que el legislador estatal ya preveía que no todas las CCAA iban a desarrollar una organización ad hoc de defensa de la competencia a imagen y semejanza de la organización estatal, sino que cada una de ellas, en función de sus características, optaría por un modelo concreto, lo que podría conllevar, como de hecho ocurrió, una desigual aplicación de la legislación de competencia en función del modelo de organización escogido por cada Comunidad Autónoma.

De este modo, en función de la fórmula de organización escogida podíamos encontrarnos con CCAA que sólo tenían un organismo de instrucción atribuyendo la potestad de resolución de sus expedientes a la autoridad de competencia estatal, CCAA que tenían una organización completa para desarrollar sus competencias ejecutivas en defensa de la competencia y, por último, CCAA que no crearon ningun órgano u organismo específico a tales efectos en cuyo caso seguirán conociendo de los asuntos relativos a la libre concurrencia los órganos estatales ${ }^{6}$. Ante estas distintas opciones la Ley 1/2002, de coordinación de competencias entre el Estado y las CCAA, incluyó, concretamente en su inicial art. 4.1, una fórmula de colaboración dirigida especialmente a aquellas CCAA que en un principio no quisieran desarrollar una organización específica o acabada de defensa de la libre competencia; dice así:

«El Servicio de Defensa de la Competencia y el Tribunal de Defensa de la Competencia podrán celebrar convenios de colaboración con los

toridades autonómicas de defensa de la competencia en vías de extinción», Documento de Trabajo, Serie Política de la Competencia (CEU San Pablo), núm. 31/2012.

${ }_{6}$ Murcia (Decreto 13/2004, de 13 de febrero) y Canarias (Decreto 118/2006, de 1 de agosto del Servicio de Defensa de la Competencia) crearon una unidad inserta en la Administración autonómica con competencias de instrucción, encargándose la autoridad de competencia estatal de la resolución de los procedimientos sancionadores que se pudieran incoar por dichas autoridades autonómicas, a través de la fórmula de distintos convenios bilaterales celebrados entre el Estado y los respectivos gobiernos autonómicos. 
órganos competentes de las Comunidades Autónomas para la instrucción y resolución de los procedimientos que tengan por objeto conductas que sean competencia tanto del Estado como de estas últimas. Dichos convenios establecerán las fórmulas y mecanismos concretos a través de los cuales se instrumentará la referida colaboración»

Era de suponer, por tanto, que habría CCAA que no desarrollarían una organización específica atribuyendo, mediante el empleo del instrumento de los convenios de colaboración, al Estado la facultad para instruir y resolver los expedientes de ámbito infraautonómico que serían de los relativos a procedimientos sancionadores y a la concesión de autorizaciones singulares que son los ámbitos de defensa de la competencia que en un principio son de competencia autonómica.

En un primer momento, sólo tres CCAA, Cataluña, Galicia y Madrid, desarrollaron una organización específica en defensa de la competencia en términos muy parecidos si bien el tipo de norma empleada para ello fue distinto en Cataluña y Madrid -reglamento y Ley- frente a Galicia-Ley- ${ }^{7}$. Con carácter general estas tres CCAA crearon una estructura organizativa idéntica a la del Estado, de tal modo que la instrucción y las labores de inspección e investigación se encomendaron a un órgano específico, mientras que la fase de resolución se encontraba atribuida a otro órgano que se configuraba como un organismo de carácter administrativo, con personalidad jurídica propia, que ejercía sus funciones con plena independencia y sometimiento al ordenamiento jurídico.

En cuanto a sus fines, como no podría ser de otra manera a tenor de la STC 208/1999, se circunscriben a preservar el funcionamiento del mercado intracomunitario y procurar una competencia efectiva del mismo, mediante el ejercicio de las funciones de instrucción, resolución, inspección, así como la consultiva que viene especialmente atribuida a dichos organismo por sus Leyes correspondientes ${ }^{8}$.

7 La CA Catalana lo hizo a través del Decreto 222/2002, de 27 de agosto, por el que se crean los órganos de defensa de la competencia de la Generalidad de Cataluña, lo que había sido autorizado previamente por la Ley 21/2001, de 28 de diciembre, de medidas fiscales y administrativas; la CA Gallega por medio de la Ley 6/2004, de 12 de julio, reguladora de los órganos de defensa de la competencia de la Comunidad Autónoma de Galicia, y, finalmente, Madrid aprobó el Decreto 239/2001, de 11 de octubre por el que se establece la estructura orgánica de la Consejería de Economía e Innovación tecnológica de la Comunidad de Madrid y la Ley 6/2004, de 28 de diciembre, de creación del Tribunal de Defensa de la Competencia de la Comunidad de Madrid.

${ }^{8}$ Sobre los TDC autonómicos y su organización inicial específica, vid., GUILLÉN CARAMÉS, J., «La creación de órganos administrativos de defensa de la competencia por las Comunidades Autónomas», Revista General del Derecho, IUSTEL, 2003; AMILS AR- 


\subsection{La nueva Ley 15/2007 de defensa de la competencia y su incidencia en el modelo de autoridad autonómica de competencia}

La reforma profunda de la legislación de competencia que se originó con la reforma de la Ley 16/1989, a través de la Ley 15/2007, que cambia sustancialmente la estructura, funciones y potestades de las autoridades de competencia, fundamentalmente la de ámbito estatal, esto es la actual Comisión Nacional de los Mercados y de la Competencia (CNMC) ${ }^{9}$, iba a acarrear la reestructuración del modelo de autoridad autonómica de competencia que en líneas generales ha sido muy similar al modelo configurado por el Estado ${ }^{10}$. El cambio de un modelo dual de aplicación de la LDC a través de dos organismos (normalmente el servicio de defensa de la competencia por un lado y, por otro, el Tribunal) hacia un modelo de organismo único, conllevó por parte de las Comunidades Autónomas un replanteamiento del modelo, así como una nueva configuración de sus autoridades autonómicas al sistema de organismo único con la finalidad de que pudieran prestar con mayor grado de eficacia y eficiencia las nuevas funciones que se establecen en la nueva LDC.

Conviene resaltar que ni la LDC ni la Ley 1/2002 condicionan o establecen modelos concretos de naturaleza organizativa que deban seguir las CCAA para poder ejercer sus competencias de ejecución sobre la defensa de la competencia. Sin embargo, en líneas generales dichos modelos se han caracterizado, normalmente, por un claro seguimiento del modelo de organización previsto por la legislación de competencia para la Administración General del Estado.

En este sentido, se han manifestado las CCAA de Galicia, Cataluña, País Vasco y Andalucía ${ }^{11}$ que han procedido a reestructurar su modelo de autoridad de competencia por medio de nuevas normas que han adaptado las nuevas exigencias que demanda el Derecho de la Competencia con el fin de poder cumplir adecuadamente con los fines que prevé la LDC, así

NAL, R., «Los nuevos tribunales autonómicos de defensa de la competencia», GJ, núm. 224, 2003, págs. 66 y ss.

${ }_{9}$ Creada por la Ley $3 / 2013$, de 4 de junio.

${ }^{10}$ En la actualidad se encuentra en estado de tramitación parlamentaria en el Congreso de los Diputados el Proyecto de Ley recreación de la Comisión Nacional de los Mercados y de la Competencia, presentado por el Gobierno el 10 de octubre de 2012, y que tiene como finalidad la fusión de la CNC con los organismos reguladores de carácter sectorial (energía, telecomunicaciones, servicios postales, transportes)

${ }^{11}$ Ley 1/2011, de 28 de febrero, reguladora del Consejo Gallego de la Competencia; Ley 1/2009, de 12 de febrero, de la Autoridad Catalana de Competencia; Ley 1/2012, de 2 de febrero, de la Autoridad Vasca de Competencia y la Ley 6/2007, de 26 de junio, de Promoción y Defensa de la Competencia de Andalucía. 
como la legislación comunitaria de competencia. Por otro lado, otras CCAA que, inicialmente habían creado sus autoridades de competencia, han decidido su supresión, fundamentando la misma en criterios de ahorro económico, como han sido los casos de la Comunidad de Madrid y Castilla-La Mancha ${ }^{12}$.

La nueva configuración de este nuevo modelo de autoridades autonómicas de la competencia se sustenta, como señala el preámbulo de la Ley 1/2009, de 12 de febrero, de la Autoridad Catalana de Competencia, obviamente para dicha CA, si bien el resto de las normas autonómicas que crean estas nuevas autoridades de competencia emplean argumentos similares, sobre los siguientes pilares:

«El nuevo modelo que se implanta en estas CCAA pretende reforzar la capacidad para incorporar, con operatividad y eficacia, los parámetros de modernización que exige la normativa europea, relativos a aspectos como la importancia de las políticas de competencia para los consumidores y usuarios; el refuerzo del enfoque económico en la metodología de trabajo de las autoridades de competencia; el aprovechamiento de los beneficios que aportan la cooperación entre autoridades de la competencia y los intercambios de información y experiencia entre estas autoridades; pero sobre todo, el fomento de las políticas de promoción de la competencia de carácter proactivo

Un modelo de competencia moderno y eficaz debe dar una respuesta solvente a la vertiente reactiva de la política de competencia, que es lo que sanciona conductas prohibidas, a partir de las denuncias interpuestas o los indicios obtenidos. Pero con ello no basta, ya que, adicionalmente, debe aplicar una política preactiva caracterizada por el fomento y la promoción de la competencia. Esta segunda vertiente se concibe como un instrumento de política económica fundamentada en el análisis y estudio de los mercados, capaz de suministrar información útil para la acción de gobierno, sugerir mejoras en la legislación sectorial orientadas a eliminar barreras de entrada, corregir prescripciones anticompetitivas, mejorar y simplificar la regulación, así como divulgar la cultura de la competencia con el fin de favorecer que las empresas adopten estrategias procompetitivas

En primer lugar, uno de los elementos centrales sobre lo que ha girado la reforma de las autoridades autonómicas de competencia ha sido el de

${ }_{12}$ En la Comunidad de Madrid lo prevé el art. 9 de la Ley 6/2011 de la Comunidad de Madrid, de 28 de diciembre, de medidas fiscales y administrativas; mientras que en la Comunidad castellano manchega se ha suprimido la autoridad de competencia por medio del Decreto 177/2011, de 14 de julio, de supresión de los órganos de defensa de la competencia de Castilla-La Mancha. Sobre la extinción de las autoridades de competencia autonómicas, vid., MARcos, F., «Autoridades autonómicas...», op. cit., págs. 5 y ss. 
fortalecer la independencia de este tipo de organismos encargados de la defensa de la competencia y lograr la necesaria integración en un organismo único de los cometidos de instrucción y resolución de expedientes que hasta la fecha venían siendo desarrollador por dos órganos diferenciados. Este objetivo se ha conseguido mediante la creación de una autoridad única de competencia. De esta manera, la integración en una única institución se hace respetando la separación funcional y orgánica de las dos funciones de instrucción y resolución de los expedientes sancionadores, salvaguardando la independencia de la fase de instrucción y la seguridad jurídica de las partes que puedan resultar afectadas por la resolución final. Así, lo han recogido las Leyes reguladoras de estas nuevas autoridades de competencia que han configurado a las mismas como organismos autónomos, con personalidad jurídica propia y plena capacidad de obrar para ejercitar sus funciones que son fundamentalmente las de preservar, garantizar y promover la existencia de una competencia efectiva en los mercados en su respectivo ámbito autonómico. Para cumplir son sus funciones eficazmente sus normas de creación acentúan la importancia de la independencia funcional y orgánica de los mismos, estableciendo que deben actuar con autonomía orgánica, financiera y funcional; con plena independencia de las Administraciones públicas y de los agentes económicos, con el fin de evitar la denominada captura del regulador.

En segundo lugar, las leyes autonómicas de creación de estas autoridades de competencia persiguen como otro objetivo esencial el reforzamiento de estas instituciones para poder obtener una eficaz persecución y sanción de las conductas contrarias a la competencia así como un nivel adecuado de competencia efectiva en los mercados autonómicos, siguiendo la línea de acción de la LDC y las nuevas tendencias que se están desarrollando a nivel europeo en este ámbito material. Entre estas nuevas funciones debe destacarse, como ya hemos tenido ocasión de estudiar en apartados anteriores, la actividad de promoción de la competencia que está llamada a jugar un papel fundamental en la política moderna de competencia y que tiene una marcada finalidad de regulación de los operadores en los mercados.

Finalmente, debe destacarse que desde una perspectiva orgánica, las nuevas autoridades autonómicas de competencia se estructuran en tres órganos fundamentales a semejanza de la CNMC: el Presidente, el Consejo y la Dirección de Investigación. El primero de ellos tienen atribuidas las funciones de dirección, coordinación y representación de la autoridad; el Consejo o Tribunal es el órganos máximo de resolución y decisión de la autoridad; y, por último, el Director de Investigación suele tener encomendadas, en general, las funciones de instruir los expedientes, de preparara los informes relativos a las conductas prohibidas por la LDC, así como los relativos al control de concentraciones empresariales. 


\section{LA APLICACIÓN DESCENTRALIZADA DEL DERECHO DE LA COMPETENCIA}

\subsection{La necesidad de garantizar la coordinación en la aplicación del Derecho de la Competencia: criterios empleados por la Ley 1/2002}

Dos son los objetivos que de forma esencial se persigue con la aprobación de la Ley 1/2002. Primero, lograr definir las diferentes atribuciones que como poderes jurídicos, tanto en las funciones legislativas como en las ejecutivas, han de permanecer en la órbita del Estado. En segundo lugar, la de fijar las técnicas de coordinación entre los órganos estatales y autonómicos de defensa de la competencia, con la finalidad de garantizar de este modo la uniformidad de la aplicación de las normas de competencia en todo el mercado nacional, junto con los mecanismos de cooperación y de información recíproca.

En este sentido, y como se estudiará en los epígrafes siguientes de este trabajo, el correcto funcionamiento de esta Ley va a depender en numerosas ocasiones, del grado de colaboración que las distintas administraciones con competencias sobre la defensa de la libre concurrencia vayan a tener entre sí. Este principio de cooperación, junto con el de coordinación, van a ser los motores que impulsen la maquinaria de esta nueva Ley en el sentido y con la intensidad que tendremos ocasión de examinar. Ya de su propia Exposición de Motivos, e incluso de su propio enunciado, se deduce esta afirmación, que va a verse plasmada desde un punto de vista procedimental en el intercambio de información entre las autoridades encargadas de velar por la defensa de la competencia. Y es que, como señala J. E. SORIANO «la continuidad en el tejido de las funciones públicas, creando sinergias, cooperación, colaboración, resultan esenciales para garantizar el cometido de las funciones públicas al servicio de los objetivos e intereses generales, evitando despilfarros, holguras, y otras carísimas e ilegales disfunciones administrativas $\rangle^{13}$.

En este apartado examinaremos la delimitación que lleva a cabo la Ley $1 / 2002$ en orden a determinar genéricamente el ejercicio de las competencias por parte del Estado y de las Comunidades Autónomas, según los fundamentos jurídicos de la STC 208/1999. Debido a la complejidad que se deriva del Derecho de Competencia, habrá que tener en cuenta a la hora de delimitar cuándo pueden ejercer sus competencias las autoridades de competencia estatal y cuándo las autonómicas, diversos criterios, impregnados de un alto grado de indeterminación debido a la especial casuística que tiene la correcta interpretación de determinados conceptos con un fuerte contenido económico y, por ello, con un alto grado de variabilidad, que son especialmente im-

${ }^{13}$ Vid., «Comentario de urgencia a la Ley 1/2002», GJ, núm. 218, 2002, pág. 12. 
portantes dentro de este ámbito, especialmente en la definición del mercado y la determinación del poder del mercado de un operador, lo que sin duda deberá tenerse en cuenta para ver si se trata de un ámbito suprautonómico o que afecte al mercado nacional, en cuyo caso la competencia corresponderá a los órganos de competencia del Estado; o, por el contrario se trata de un ámbito infrautonómico y entonces de competencia autonómica.

\subsubsection{Los puntos de conexión. La necesidad de una precisa delimitación de los mismos}

La Ley 1/2002 introduce el concepto jurídico indeterminado de los puntos de conexión como técnica tendente a definir y concretar el alcance territorial de determinados hechos con el fin de poder determinar cuál de las instancias territoriales -Estado o Comunidades Autónomas-va a poder ejercitar su competencia ejecutiva en la defensa de la competencia ${ }^{14}$. Si bien la introducción de los puntos de conexión pudo causar cierta sorpresa en la doctrina administrativa, como advierte X. Arzoz, especialmente, en este ámbito de delimitación competencial donde las competencias tienen en principio un carácter territorial, hay que señalar que este concepto no resulta extraño al Derecho Público desde que nuestra CE atribuyó desde un primer momento funciones legislativas y ejecutivas a los entes autonómicos sobre diversas materias ${ }^{15}$. En este sentido, el empleo de los puntos de conexión puede examinarse desde una doble perspectiva: por un lado en aquellos supuestos derivados de la existencia de una pluralidad de ordenamientos de ámbito territorial, esto es, cuando las competencias legislativas sobre una determinada materia se encuentren atribuidas de forma exclusiva o compartida a las CCAA; y, de otro, cuando nos enfrentamos a la delimitación de competencias ejecutivas, bien entre las CCAA y el Estado, bien entre las CCAA entre sí. Será sobre esta última vertiente sobre la que se centra la Ley 1/2002 al

${ }^{14}$ Como señala I LASAgabaster «por puntos de conexión se viene entendiendo «aquellas circunstancias cuya concurrencia implica que una determinada actividad se someta al régimen jurídico o al régimen de intervención de una o varias Comunidades $\mathrm{Au}-$ tónomas o del Estado», vid., «El territorio y la eficacia de las normas jurídicas», en Informe Pi i Sunyer sobre CCAA, II, Instituto de Derecho Público, 1994, págs. 791 y ss.

${ }^{15}$ Cfr., "Comunidades Autónomas, puntos de conexión y defensa de la competencia», $R A P$, núm. 64, 2002, págs. 11 y ss. Señala el citado autor que el empleo de la técnica de los puntos de conexión se ha venido desarrollando frecuentemente en otras ramas jurídicas, concretamente, en el Derecho internacional privado donde constituyen un elemento particular de las llamadas normas de conflicto. En este sentido, las normas de conflicto son «aquellas normas de Derecho internacional privado que, para la regulación de la situación privada internacional, determinan, de entre los distintos ordenamientos vinculados con el supuesto, cuál de ellos debe regir dicha situación». 
establecer los puntos de conexión que marcarán el ejercicio de las competencias ejecutivas en defensa de la competencia entre el Estado y las Comunidades Autónomas.

El art. 1 de la Ley 1/2002 establece los puntos de conexión que delimitan de forma general el ejercicio de las competencias por parte del Estado y de las Comunidades Autónomas en la defensa de la competencia. Estos puntos tienen su fundamento en la STC 208/1999, concretamente en su Fundamento Jurídico $7^{\circ}$, según el cual la competencia se halla limitada a aquellas actuaciones ejecutivas que hayan de realizarse en el territorio de cada Comunidad Autónoma y que no afecten al mercado supraautonómico. Ello supone que la competencia del Estado se extiende no sólo a la formación, sino también a todas las actuaciones ejecutivas en relación con aquellas prácticas que puedan alterar la libre competencia en el ámbito supraautonómico o en el conjunto del mercado nacional, aunque tales actuaciones se realicen en el territorio de una Comunidad Autónoma ${ }^{16}$.

${ }^{16}$ Debe señalarse que la jurisprudencia del TC no siempre ha seguido este criterio de la dimensión supracomunitaria para atribuir el ejercicio de una determinada competencia al Estado. En este sentido, la STC 13/1992 ha considerado necesario justificar en cada caso la necesidad de una gestión centralizada de la competencia para atribuir la misma al Estado. Así, por ejemplo, la STC 196/1997, de 13 de noviembre, en que el problema a resolver era la conformidad de la atribución estatal de una competencia ejecutiva en materia de legislación de la propiedad intelectual, señaló que la atribución de la autorización a la competencia estatal «está plenamente justificada, pues trata de asegurar el mantenimiento de un régimen jurídico unitario de la gestión de explotación de los derechos de la propiedad intelectual y de la uniformidad de la ordenación jurídica de la materia». De todas formas aquella exigencia es una exigencia material y no meramente formal como ha precisado la STC 242/1999, de 21 de diciembre, que al hilo de un conflicto de competencia relativo a la concesión de ayudas a empresas turísticas señaló que el hecho de que las agrupaciones de empresas en «supuestos de supraterritorialidad puedan resultar beneficiarias también de las ayudas», ello no supone la atracción «hacia el Estado de la competencia de gestión, máxime cuando cabe establecer los puntos de conexión necesarios para que se realice la gestión autonómica o, alternativamente, justificar su improcedencia para mantener la gestión centralizada». En definitiva, puede establecerse, como hace el TC en su STC 190/2000, de 13 de julio, que resulta especialmente importante para nuestro objeto de estudio pues el título competencial examinado es el 149.1.13 $\mathrm{CE}$ que es uno de los títulos competenciales que el Estado tiene para actuar en defensa de la competencia, señalando que «la perspectiva territorial general que es propia del art. 149.1.13 $\mathrm{Ce}$ no puede tener como consecuencia necesaria la centralización de toda la normativa que deba establecerse, ni tampoco de todas las medidas de ejecución que hayan de adoptarse, puesto que ello supondría, sencillamente, el desapoderamiento de las competencias autonómicas con las que concurre. En definitiva, la centralización de las funciones de formación y de ejecución sólo puede tener lugar, como venimos insistiendo, en supuestos excepcionales que aparezcan plenamente justificados, pues la regla ha de ser la de que las Comunidades Autónomas competentes desarrollen normativamente los Planes y los apliquen, incluso 
Pues bien, el citado art. 1 Ley 1/2002, en su apartado primero reproduce, casi textualmente, este pronunciamiento señalando que

"Corresponde al Estado el ejercicio de las competencias reconocidas en la Ley 16/1989, de 17 de julio, de Defensa de la Competencia, respecto de los procedimientos que tengan por objeto las conductas previstas en los artículos 1, 6 y 7 de la mencionada Ley, cuando las citadas conductas alteren la libre competencia en un ámbito supraautonómico o en el conjunto del mercado nacional, aun cuando el ejercicio de tales competencias haya de realizarse en el territorio de cualquiera de las Comunidades Autónomas»

El empleo de los dos criterios -alterar la libre competencia en un ámbito supraautonómico o alterar la libre competencia en el conjunto del mercado nacional- como elemento de juicio para entender admitida la entrada en juego de la competencia ejecutiva del Estado en vez de la autonómica, han sido objeto de crítica por la doctrina científica por no atender a la denominada doctrina de los efectos que predica que cada Estado aplicará su legislación de defensa de la competencia respecto a aquellas conductas o prácticas que se produzcan dentro de su territorio, doctrina que es la generalmente reconocida en el Derecho de la competencia, y es asimismo acogida por el legislador español y comunitario ${ }^{17}$. Así, por un lado, el art. 1.1. LDC señala que «se

cuando su ejecución pueda tener alcance supraterritorial, pues es responsabilidad del Estado en estos casos fijar los puntos de conexión que permiten la ejecución autonómica de las medidas, dado que hemos dicho que el traslado de la titularidad de la competencia de gestión sólo puede tener lugar, como se apuntó en la STC 329/1993, cuando, además del alcance territorial superior al de una Comunidad Autónoma del objeto de la competencia, la actividad pública que sobre él se ejerza no sea susceptible de fraccionamiento $\mathrm{y}$, aun en este caso, cuando dicha actuación no pueda llevarse a cabo mediante mecanismos de cooperación o coordinación».

${ }_{17}$ Esta doctrina se aplica como criterio de conexión con la correspondiente legislación de defensa de la competencia. De este modo, cada Estado aplica su legislación antitrust a los efectos restrictivos que un acuerdo o una práctica restrictiva tenga por objeto producir en su territorio, sin perjuicio de que la práctica o sus responsables se localicen en un tercer Estado. En este sentido, esta doctrina se concibe, como señala ARzoz, X., «como una posible aplicación extraterritorial de la legislación interna en virtud de dos circunstancias. Por un lado, cada sujeto de Derecho internacional solo pretende salvaguardar la libre competencia en el ámbito territorial sobre el que ejerce su jurisdicción. Por otro lado, los mercados nacionales operan en un contexto de mercados abiertos, y por tanto ni las conductas anticompetitivas con repercusión en el mercado nacional ni sus responsables se localizan necesariamente en éste». Continúa el citado autor señalando que «la producción de efectos internos es el punto de conexión necesario y suficiente para el ejercicio de la competencia en materia de defensa de la competencia», en este sentido, se trata por tanto, de un punto de conexión «suficiente porque cada Estado actúa sólo en relación con los efectos que se producen en su territorio, con independencia de que esos efectos internos 
prohíbe todo acuerdo, decisión o recomendación colectiva, o práctica concertada o conscientemente paralela, que tenga por objeto, produzca o pueda producir el efecto de impedir, restringir, o falsear la competencia en todo o en parte del territorio nacional»; $\mathrm{y}$, de otro, el art. 101.1 TFUE establece que «serán incompatibles con el mercado común y quedarán prohibidos los acuerdos entre empresas, las decisiones de asociaciones de empresas y las prácticas concertadas que puedan afectar al comercio entre los Estados miembros y que tengan por objeto o efecto impedir, restringir o falsear el juego de la competencia dentro del mercado común». Por lo tanto, los críticos con la técnica empleada por la Ley $1 / 2002$ a la hora de definir los puntos de conexión concluyen que el legislador estatal debiera haber retenido el criterio de los efectos como punto de partida también para la atribución de las competencias autonómicas ${ }^{18}$.

El legislador estatal ha acogido en parte esta doctrina de los efectos si bien con un carácter más restringido, en el sentido de que para que una CA pueda ejercer su competencia ejecutiva y de este modo pueda entrar a conocer sobre la adecuación o no a la LDC de una determinada conducta o práctica restrictiva, resulta necesario que los efectos de la misma se produzcan de forma exclusiva dentro de su territorio, puesto que en caso contrario sería el Estado el competente para actuar. Esta tesis es la mantenida por la STC 208/1999, así como por la mayoría de los autores que han entrado a comentarla reconociendo que las CCAA sólo podrán ejercitar sus competencias ejecutivas sobre la defensa de la competencia en relación con aquellas prácticas cuyos efectos no superen el territorio correspondiente ${ }^{19}$. De este modo

sean exclusivos, coincidentes o adicionales a los producidos en otros Estados». Por ello la aplicación de la doctrina de los efectos a la defensa de la competencia no precisa de la exclusividad de los efectos internos y, en consecuencia, no impide la posibilidad de intervenciones paralelas o sucesivas por parte de las autoridades competentes de una pluralidad de Estados. En general, sobre estos aspectos, vid., «Comunidades Autónomas, puntos...», cit., págs. 42 y ss.

18 Ibídem., pág. 49; y CASES, LL., «La competencia en España 1999», Anuario de la Competencia 1999, Marcial Pons-ICo, 2000, pág. 20.

19 Vid., entre otros, Magide Herrero, M., «El reparto competencial en materia de defensa de la competencia...», cit., págs.; Lopez Benitez, M., «Defensa de la competencia. Perspectivas abiertas tras la STC 208/1999», RarAP, núm. 17, 2000, págs. 134 y ss.; Belando Garín, B., «Defensa de la competencia y comercio interior», REDA, núm. 106, pág. 271. En contra de esta interpretación se muestra ARzoz, X., «Comunidades Autónomas, puntos de...», cit., págs. 50 y ss., para quien el uso de los dos sintagmas utilizados por el TC y, ulteriormente por el legislador (ámbito supraautonómico y conjunto del mercado nacional), no tienen sustantividad propia sino que son la misma cosa, de tal modo que deben ser interpretados de forma única de tal modo de «que sólo el sintagma «en el conjunto del mercado nacional» sería el indispensable elemento integrante del título competencial estatal». 
el legislador estableció, como ya se ha indicado, un doble criterio para conocer cuándo una determinada práctica que pueda contravenir lo dispuesto en la LDC debe ser fiscalizada por los órganos estatales de defensa de la competencia: por un lado, que la práctica restrictiva altere o pueda alterar un ámbito supraautonómico, $\mathrm{y}$, de otro, que la misma pueda afectar al conjunto del mercado nacional.

La elección de esta fórmula dicotómica por el legislador ha originado una fuerte crítica a la misma por la inexactitud e indeterminación de estos dos sintagmas que pueden ocasionar problemas a la hora de interpretar los mismos y, por ende, a la hora de atribuir el ejercicio de la competencia ejecutiva sobre la defensa de la competencia bien al Estado bien a las CCAA. El epicentro de las posturas contrarias a la opción adoptada por el legislador que, a mi juicio, lo que se limitó a realizar fue una mera transposición del contenido de la STC 208/1999 con una técnica jurídica poco acertada, radican en el contenido que debe tener la expresión ámbito supraautonómico que identifican con el conjunto del mercado nacional, de tal modo que la primera debe entenderse integrada dentro de la segunda que tiene un contenido más amplio. De este modo y, de acuerdo con esta postura, quedarían correctamente salvaguardadas las competencias ejecutivas de las CCAA y no se produciría un vaciamiento de las mismas al conocer el Estado de las conductas que alteren los ámbitos supraautonómicos ${ }^{20}$. Sin embargo, no parece que esta sea la interpretación que debe hacerse pues de la lectura e interpretación gramatical y teleológica del art. 1 Ley 1/2002 no cabe inferirse tal deducción. En mi opinión, una cosa es que una conducta altere o pueda alterar un ámbito supraautonómico (así, por ejemplo, la instalación de una gran superficie comercial o un casino en una localidad ubicada en una zona limítrofe entre dos CCAA puede implicar que estas empresas puedan realizar conductas prohibidas por la LDC y desplegar con ello efectos contrarios a la defensa de la competencia en un ámbito supraautonómico y no por ello afectar al conjunto del mercado nacional), y otra muy distinta que afecte al conjunto del mercado nacional que es una realidad más amplia (por ejemplo, que una aerolínea de carácter regional pacte precios con el resto de las aerolíneas españolas). De todas formas hay que convenir que para que el Estado pueda accionar su competencia ejecutiva en el supuesto de conductas anticompetitivas que puedan tener efectos supraautonómicos resultará necesario que estos tengan una especial relevancia para el Derecho de la competencia en ambas instancias territoriales, de tal modo que si la conducta o práctica restrictiva sólo tiene una especial incidencia en una CA desplegando tan sólo efectos de escasa importancia para la defensa de la competencia en otra u otras CCAA el Estado no

${ }^{20}$ Vid., Arzoz, X., «Comunidades Autónomas, puntos de...», cit., págs. 51 y ss. 
deberá intervenir y será la CA donde los efectos anticompetitivos desplieguen toda su eficacia la competente para actuar su competencia ejecutiva ${ }^{21}$.

Acto seguido, en el apartado segundo del art. 1 Ley $1 / 2002$, se establecen los criterios y reglas que deberán permitir solventar en qué supuestos debe entenderse que una determinada conducta que sea susceptible de alterar la libre competencia de un operador económico va a tener una trascendencia supraautonómica o va afectar al mercado nacional, lo que implicará la puesta en marcha de los órganos estatales de defensa de la competencia, que deberán adoptar, como se analizará más adelante, las correspondientes medidas de información dirigidas a los órganos autonómicos con el propósito de que tengan noticia de la apertura de una acción administrativa tendente a examinar una posible conducta infractora de la LDC, lo que a su vez puede suponer en el supuesto de que los órganos autonómicos no estén de acuerdo con la calificación que los órganos estatales han realizado de la conducta a efectos de poder dilucidar la Administración competente, la activación de los mecanismos de resolución de conflictos previstos en el art. 2 de la Ley 1/2002.

Sin entrar en mas detalles sobre este último punto, es menester en este momento analizar los criterios empleados tanto por la Ley $1 / 2002$, tendentes a poder discernir cuando una conducta que altere la libre competencia va a afectar a un ámbito supraautonómico o al conjunto del mercado nacional, lo que conllevará que los órganos competentes para examinar si la misma es contraria a la LDC son el SDC y el TDC del Estado. Pero como paso previo al examen de estos criterios, pienso que es necesario primero analizar los conceptos relevantes para la defensa de la competencia en orden a determinar si una conducta altera la competencia en un mercado y cómo se determina este a tal efecto. Resulta, por tanto, evidente que sólo en función de la deli-

${ }^{21}$ Podría tenerse en cuenta lo previsto en el art. 6 LDC que señala: «Cunado así lo requiera el interés público, la comisión Nacional de la Competencia, mediante decisión adoptada de oficio podrá declarar, previo informe del Consejo de Defensa de la Competencia, que el artículo 1 no es aplicable a un acuerdo, decisión o práctica, bien porque no se reúnan las condiciones del apartado 1 o bien porque se reúnan las condiciones del apartado 3 de dicho artículo. Dicha declaración de inaplicabilidad podrá realizarse también con respecto al artículo2 de esta Ley». Igualmente, señala PRAT MASIP, C., que se echa en falta en el texto de la Ley 1/2002 «un factor de minimis en el reparto de competencias teniendo en cuenta que el principio fundamental en que se basa el mismo es la teoría del efecto», por tanto, partiendo de la base que para que se produzca el correcto ejercicio de las competencias ejecutivas «por parte de uno u otro órgano antitrust, deben producirse efectos antitrust en el territorio en causa, entendemos que el efecto debería ser sustancial -como nos tiene acostumbrado el derecho de la competencia en el campo sustantivo; así el efecto puede adquirir relevancia jurídica», vid., «Aspectos procesales de la Ley 1/2002 de coordinación de las competencias del Estado y las Comunidades Autónomas en materia de defensa de la competencia», Derecho de la competencia europeo y español, Dykinson-URJC,IV, 2004, pág. 140. 
mitación de los conceptos básicos de la defensa de la competencia-mercado de referencia, mercado geográfico, mercado de producto, etc.- y a partir de su correcta definición se podrán examinar los criterios establecidos por la Ley $1 / 2002^{22}$.

\subsubsection{Criterios previstos por la Ley $1 / 2002$ para delimitar cuando una conducta altera la libre competencia en un ambito supraautonomico o en el conjunto del mercado nacional}

Con un carácter general $\mathrm{y}$, un tanto inconcreto, se establece el primer criterio para conocer cuándo una conducta que sea contraria a la libre competencia va a tener que ser conocida por los órganos estatales, en el primer apartado del art. 1 de la Ley 1/2002. De este modo el art. 1.2.a) Ley $1 / 2002$ establece al respecto lo siguiente:

"Cuando una conducta altere o pueda alterar la libre competencia en un ámbito supraautonómico o en el conjunto del mercado nacional, entre otras causas, por la dimensión del mercado afectado, la cuota de mercado de la empresa correspondiente, la modalidad y el alcance de la restricción de la competencia, o sus efectos sobre los competidores efectivos o potenciales y sobre los consumidores y usuarios, aun cuando tales conductas se realicen en el territorio de una Comunidad Autónoma»

Cuatro son los criterios que deben tenerse en cuenta, si bien no se aclara en el texto de la Ley si para que se estime que la conducta reviste un carácter supraautonómico o afecta al mercado nacional, deben darse todos ellos de forma conjunta o, por el contrario deben ser tenidos en cuenta de forma individual, bastando que se dé uno de ellos para que la conducta sea considerada de carácter supraautonómico o que afecta al mercado nacional. A este respecto, se ha pronunciado, de forma un tanto confusa MARTINEZ LAGE, señalando que, en su opinión, «estos cuatro criterios (...) no deben ser utilizados individualmente sino tomados como parámetros de utilización conjunta para determinar si nos hallamos en presencia de una conducta que pueda afectar a la unidad del mercado nacional. Es más, en algún caso, la débil dimensión de alguno de ellos (por ejemplo, «la modalidad y alcance») podría ser determinante de la no atribución de la competencia al Estado que podría venir determinada por otro de los parámetros (por ejemplo, la dimensión del mercado)», lo que realmente arroja poca claridad sobre la cuestión. En general, puede

${ }^{22} \mathrm{Si}$ bien en orden a delimitar estos conceptos, surge el problema de qué autoridad de competencia, estatal o autonómica, será la encargada de efectuar este análisis económico que tendrá como consecuencia fundamental la determinación del ente competente para ejercitar la competencia ejecutiva sobre este ámbito. 
decirse que la respuesta a este interrogante va a depender de la categoría de normas de Derecho de la Competencia que se esté aplicando. Así, si se examina un acuerdo restrictivo entre empresas, su poder de mercado determinará la gravedad de la restricción, lo que será tenido en cuenta a la hora de determinar si restringe la competencia y si afecta al comercio supracomunitario. En cambio, si se trata de una conducta relacionada con el abuso de posición dominante serán otros los criterios que deban emplearse para ver si el mismo afecta al mercado nacional o no.

i) La dimensión del mercado. Este es el primero de los criterios que se emplean para determinar si se afecta a la unidad del mercado nacional. Su razón de ser es evidente, al igual, que su origen de procedencia del Derecho Comunitario ${ }^{23}$. Significa que en determinados supuestos puede verse afectado el mercado nacional aunque los efectos se produzcan sólo en una Comunidad Autónoma, si la dimensión del mercado es lo suficientemente extensa, intensa y preocupante. Debe observarse que para determinar la dimensión del mercado será necesario caber uso de los criterios propios del Derecho de la Competencia anteriormente enunciados. Por tanto, puede concluirse señalando que las conductas que afecten a la totalidad de una Comunidad Autónoma, difícilmente dejarán de afectar al conjunto del mercado nacional y, serán en consecuencia, de competencia de los órganos estatales de competencia.

ii) La cuota de mercado. Este es un elemento de gran importancia para determinar la relevancia geográfica de la práctica correspondiente. Este criterio resulta de difícil interpretación, pues en primer lugar debe preguntarse en qué mercado debe medirse. ¿en el nacional?, o ¿en el autonómico?. Se decanta por la primera opción MARTINEZ LAGE, argumentando que «el impacto relativo sobre la economía autonómica» hace que sea preferible su medición en el mercado nacional ${ }^{24}$. En sentido contrario, se encuentra J. E. SORIANO, para quien la cuota de mercado debe medirse «tanto en el mercado geográfico regional como en

${ }^{23}$ El TJUE viene interpretando en el ámbito del art. 102 TFUE que el territorio de un Estado miembro es una parte sustancial del mercado común, a efectos de determinar la aplicabilidad de este artículo a una conducta determinada (STJCE Michelin, As. 322/81, de 9 de noviembre de 1983). En el ámbito del art. 101 TFE, la jurisprudencia comunitaria considera que «una práctica colusoria que se extienda a todo el territorio de un Estado miembro tiene por efecto consolidar compartimentaciones de carácter nacional, que obstaculizan de este modo la interpretación económica perseguida por el Tratado», y supone, por tanto, una afectación a los intercambios comunitarios (STJCE Wouters, C-309/99, de 19 de febrero de 2002). Sobre este tema, vid., MARTinez LAGE, S., «La aplicación de...», cit., pág. 6.

${ }^{24}$ Ibidem. 
el nacional y, luego, entrar en el debate correspondiente» ${ }^{25}$. En mi opinión, la realidad práctica será le encargada de dilucidar esta controversia, pues en función de qué órgano sea el primero en actuar, nacional o autonómico, bien a instancia de parte o de oficio, le corresponderá tomar la decisión. Bien es cierto, que será deseable que en el examen de la cuota de mercado se tenga en cuenta tanto el mercado nacional como el autonómico, pues sólo así se podrá llegar a la correcta determinación de qué órgano debe actuar ${ }^{26}$.

iii) La modalidad y alcance de la restricción. Este es un criterio que aparece, igualmente enunciado en el art. 10.2 LDC para la cuantificación de las sanciones, como elemento determinante de la gravedad de las conductas ${ }^{27}$. Se trata de un factor que se tiene en cuenta para examinar la probabilidad de impacto de una conducta en otros mercados, pues si la restricción de la competencia es amplia, se puede erigir en el obstáculo para que a normal competencia entre empresas y operadores discurra por cauces de normalidad. En este sentido, piénsese en la acción coordinada de cárteles idénticos en diversas zonas localmente delimitadas del territorio nacional o, incluso, la práctica devaste y hunda un mercado local que luego no pueda recuperarse con

25 «Comentarios de...», cit., pág. 14.

26 Así, por ejemplo la Resolución del TDC de 28 de abril de 2003 (Expdte. A 322/02 Contrato tipo Comisión IBERIA) autoriza a un modelo de contrato-tipo de comisión mercantil para la promoción y venta de servicios de transporte aéreo por las agencias de viajes minoristas establecidas en España. En este supuesto resulta clara la afectación al conjunto del mercado nacional debido a la cuota de mercado que tiene IBERIA por lo que la competencia para conocer de este asunto es clara a favor del TDC estatal. En cambio, la Resolución de 8 de abril de 2003 (Expdte. A 313/02 Pacto Foodservice-Mercat) aborda la solicitud de una autorización singular para un pacto de no competencia vinculado a un contrato de arrendamiento con opción de compra de una empresa de distribución alimentaria a hostelería y restauración que tiene una cuota pequeña (2 por 100) del mercado balear, que sería le mercado geográfico relevante, por lo que en este caso correspondería a los órganos autonómicos conocer de esta autorización. Sobre los criterios de aplicación de la Ley $1 / 2002$, vid., X. Arzoz, «El impacto de los puntos de conexión de la Ley 1/2002 en la aplicación descentralizada del Derecho de la Competencia: análisis de las resoluciones adoptadas en 2003 por el TDC», en Anuario de Defensa de la Competencia, Marcial Pons-ICO, Madrid 2004, págs. 327 y ss.

${ }^{27}$ El art. 10.2 LDC dispone: «La cuantía de las sanciones se fijará atendiendo a la impo0rtancia de la infracción, para lo cual se tendrá en cuenta: a) La modalidad y el alcance de la restricción de la competencia; b) la dimensión del mercado afectado; c) La cuota de mercado de la empresa correspondiente; d) El efecto de la restricción de la competencia sobre los competidores efectivos o potenciales, sobre otras partes en el proceso económico y sobre los consumidores y usuarios; e) La duración de la restricción de la competencia; f) La reiteración en la realización de las conductas prohibidas». 
facilidad, para entender que el impacto puede ser «crucial para todo el territorio español» ${ }^{28}$.

iv) Los efectos sobre los competidores actuales o potenciales y sobre los consumidores. Resulta un criterio que encierra una especial relevancia para la unidad de mercado. En efecto, aunque una determinada conducta se lleve a cabo en el territorio de una Comunidad Autónoma, sus efectos sobre los competidores y los consumidores, de otras Comunidades Autónomas pueden ser evidentes, con el perjuicio que ello conlleva para la unidad del mercado. Imaginemos, por ejemplo, un acuerdo de precios entre los hoteleros de una Comunidad Autónoma determinada, el efecto que este tiene sobre los consumidores del resto de España es evidente.

De este modo, se puede comprobar como la dificultad que existe para delimitar los ámbitos que pueden ser de ámbito intraautonómico o de ámbito supraautonómico, implica o deriva que una determinada conducta que en un principio pudiera parecer que es de ámbito intraautonómico, en realidad no lo es, por el impacto que producen en el conjunto del mercado nacional, lo que conlleva la necesaria intervención de los órganos estatales, como así ha previsto la Ley 1/2002; si bien también puede ocurrir del mismo modo la situación contraria.

Fruto de esta dificultad se planteó el conflicto de competencia 76012007 por el Consejo de gobierno de la Comunidad de Madrid contra el Acuerdo del Pleno del TDC, por el que se mantenía la competencia de dicho órgano estatal sobre el expediente 627/2007, Estación Sur de Autobuses de Madrid, por entender que la conducta alteraba la libre competencia en un ámbito suprautonómico ${ }^{29}$. El TC resolvió dicho conflicto en su STC $71 / 2012$, de 16 de abril, en el que tras citar su jurisprudencia establecida en la STC 208/1999 y recordar su confirmación por la STC 12/2003, de 19 de junio, establece que

«las facultades en materia de defensa de la competencia corresponden al Estado siempre que la práctica pueda alterar la libre competencia en un ámbito supracomunitario o en el conjunto del mercado nacional, aunque tal acto se realice en el territorio de una Comunidad Autónoma; y, que, por el contrario, la facultad ejecutiva corresponde a la Comunidad autónoma sólo cuando concurran dos circunstancias: que la práctica

28 Ibidem.

${ }^{29}$ La conducta prohibida realizada por la empresa concesionaria de la Estación Sur de autobuses de Madrid, Esamsa, consistía en la negativa injustificada de adjudicarle a a la empresa competidora Anibal SL, en la citada estación, una taquilla de venta de billetes para la explotación de la línea internacional Santarem (Lisboa)-Madrid-Paris así como a instalar una línea telefónica en el local que dicha empresa posee en la misma estación. 
restrictiva tenga lugar en el territorio de la Comunidad y, además, que no «afecten al mercado supraautonómico» o no tenga «trascendencia sobre el mercado supraautonómico». En el presente caso resulta incontrovertido que la práctica restrictiva tuvo lugar en el territorio de la Comunidad Autónoma que plantea el conflicto, por lo que la disputa se centra en la segunda circunstancia, esto es, la determinación si la conducta imputada a Esamsa tiene o no trascendencia supraautonómica»;

De este modo, el TC desestima el presente conflicto positivo de competencia planteado al declarar que el TDC era el órgano competente para conocer del asunto:

«En efecto, la actuación imputada a Esamsa -negativa injustificada de la addudicación de una taquilla de venta de billetes a Anibal SL, necesaria para la explotación de la línea internacional Santarem (Lisboa)-MadridParis, para la que esta empresa contaba con la correspondiente autorización administrativa- trasciende el ámbito geográfico de la Comunidad Autónoma de Madrid. De acuerdo con lo manifstado por el abogado del Estado, si la conducta imputada a Esamsa fuera merecedora de reproche por producir efectos restrictivos a la competencia empresarial, dichos efectos no podrian dejar de trascender del ámbito geográfico de la Comunidad de Madrid. Al tratarse de aspectos relacionados con una línea regular de transporte de viajeros por carretera de carácter internacional con parada en Madrid la decisión sobre la denegación de la taquilla solicitada $y$ de otros servicios tiene consecuencias no sólo en el territorio de la Comunidad de Madrid, sino también en el mercado supraautonómico de transporte de viajeros.

Con independencia de la importancia en términos de negocio de la venta de billetes en taquilla d la estación de autobuses, importancia que la parte recurrente pone en duda como consecuencia de los múltiples medios que en la actualidad permiten la adquisición de títulos de transporte de viajeros por carretera, en la resolución del presente conflicto nada aporta la mayor o menor relevancia de la disponibilidad de una taquilla, decisión que interesa, en su caso, para resolver el problema de fondo, ajeno a la identificación del órgano competente desde la perspectiva constitucional. Lo relevante es que la imposibilidad de vender billetes en la Estación sur de autobuses en las mismas o similares condiciones que lo hacen sus competidores en esta línea regular, puede ser susceptible de vulnerar la libre competencia entre empresas y generar una situación de desventaja competitiva para Anibal SL, que desarrolla su actividad no sólo en el territorio de la Comunidad de Madrid sino también fuera de ducho ámbito. Por lo que la decisión material sobre la práctica imputada a Esamsa corresponde al tribunal de Defensa de la Competencia, ya que la hipotética desventaja competitiva se produciría en la explotación de una línea de transporte internacional y, pr tanto, la práctica restrictiva tendría incidencia supraautonómica». 


\subsubsection{Criterios conectados directamente con el principio de unidad de mercado para delimitar cuando una conducta altera la libre competencia en un ambito supraautonomico o en el conjunto del mercado nacional}

De semejante intensidad son los supuestos enumerados en el art. 1.2.b) Ley $1 / 2002$, en el que se atribuye la competencia a los órganos estatales de competencia en todos los supuestos en los que una conducta, además de afectar a la libre concurrencia, vulnere, principios reconocidos en nuestra CE por atentar contra el equilibrio económico entre las diversas partes del territorio nacional, al afectar de forma directa al principio de unidad de mercado. Dice así el mencionado precepto:

«Cuando una conducta pueda atentar contra el establecimiento de un equilibrio económico adecuado y justo entre las diversas partes del territorio español, implicar medidas que directa o indirectamente obstaculicen la libre circulación y establecimiento de las personas y la libre circulación de bienes en todo el territorio nacional, suponer la compartimentación de los mercados o menoscabar las condiciones básicas que garanticen la igualdad de todos los españoles en el ejercicio de los derechos y en el cumplimiento de los deberes constitucionales, aun cuando tales conductas se realicen en el territorio de una Comunidad Autónoma» ${ }^{30}$.

De nuevo, se entiende que son puntos de conexión que determinan la competencia del Estado, un conjunto de hechos que, cada uno de ellos, pueden generar una importante afección a un elemento fundamental de la libre competencia. Así, con base en una Comunidad Autónoma, aquellas conductas que pudieran, en su caso, obtener privilegios o interponer barreras a terceros que ocasionen desequilibrios interterritoriales, perfectamente conseguibles si cuentan con el apoyo o consentimiento de los poderes más cercanos sí que pueden ocasionar la alteración de un equilibrio económico adecuado y justo. De igual modo, el establecimiento de este tipo de barreras puede constituir también obstáculos a la libre circulación y establecimientos

${ }^{30}$ Como puede observarse al leer el citado precepto se trata de la integración en el mismo del contenido de los arts. 138.1, 139.2 y 149.1.1 ${ }^{\text {a }} \mathrm{CE}$, con el fin de configurar la competencia ejecutiva estatal en la defensa de la competencia. Resulta discutible la elección efectuada por el legislador pues no parece que la finalidad inmediata de la legislación de defensa de la competencia sea la de proteger estos fines de naturaleza constitucional, cuya principal finalidad es la deservir de límites al ejercicio de las competencias autonómicas para que la unidad de mercado no se vea afectada. En idénticos términos critica esta opción de la Ley 1/2002 ArzOZ, X., quien advierte que «los fines explícitos de los citados preceptos son ajenos a la defensa de la competencia y, además, no pueden ser alcanzados al amparo de cualquier título estatal, sino a través de aquellos títulos que les corresponden objetivamente», vid., «Comunidades Autónomas, puntos de...», cit., pág. 67. 
de personas y bienes, lo que conlleva que estas conductas deban ser examinadas por los órganos estatales.

También la denominada compartición de los mercados o el acceso igual a las condiciones básicas que permitan ingresar en un mercado, son aspectos lo suficientemente graves, como para comprender que el asunto concreto va más allá de los poderes normales que tienen atribuidas las Comunidades $\mathrm{Au}$ tónomas. En este sentido, señala J. E. SORIANO que «un mercado puede quedar convertido en una «isla» mediante técnicas que operando con base solamente en una autonomía separen dicho mercado total o parcialmente de la libertad de acceder al mismo. Ese es con toda evidencia, un asunto de trascendencia nacional, no solamente regional. Igual es el caso en que una acción coordinada o al menos combinada de diferentes operadores pueda llegar a romper la facilidad común de acceso económico a un territorio concreto» ${ }^{31}$.

En definitiva, cuando un mercado se compartimenta la consecuencia fundamental que de este hecho se deriva es que se produce una quiebra de todo el mercado, lo que supone, por tanto, un grave atentado a la propia unidad. Así lo ha destacado la jurisprudencia del TJCE que una vez más, nos sirve de soporte para el estudio de la descentralización de la aplicación de la defensa de la competencia en España, como consecuencia de la STC 208/1999, dice así en la conocida sentencia Consten/Grundig:

«un acuerdo entre un productor y un distribuidor que tenga como objetivo reconstituir las comparticiones nacionales en el comercio entre los Estados miembros podría ser contrario a los objetivos más fundamentales de la Comunidad (...) El Tratado cuyo preámbulo y texto dispositivo pretenden suprimir las barreras entre los Estados (...) no puede permitir a las empresas la recreación de tales barreras (ni tampoco a los poderes públicos) 》32.

En conclusión la garantía de la preservación de un mercado nacional opera como criterio de determinación de la competencia ejecutiva a los órganos estatales, de tal modo que les confiere la potestad de examinar aquellas conductas que desde esta perspectiva puedan atentar a la libre concurrencia implicando un riesgo para la unidad del mercado.

\subsection{Consecuencias jurídicas derivadas del grado de indeterminación de} los criterios establecidos en la Ley 1/2002 para la delimitación de los puntos de conexión: la posible conflictividad

Como se ha podido comprobar del examen de los diversos criterios empleados por la Ley 1/2002 en orden a delimitar qué ente territorial -Estado o

\footnotetext{
31 Ibidem., pág. 15

32 Sentencia de 13 de julio de 1966, As, 56 y 58/64.
} 
CCAA - puede accionar sus competencias ejecutivas en defensa de la competencia, se puede deducir que debido en gran parte al elevado grado de indeterminación de los denominados puntos de conexión, así como la necesidad de acudir a criterios de carácter económico de difícil concreción debido a la variabilidad de los mismos, puede afirmarse que la finalidad esencial de la citada Ley, esto es la, eliminación de las posibles controversias competenciales que pudieran surgir debido a la atribución de competencias ejecutivas tanto al Estado como a las CCAA queda un tanto difuminada ${ }^{33}$. En este sentido puede señalarse que parte de los conflictos que puedan suscitarse entre el Estado y las CCAA con ocasión del ejercicio de sus competencias ejecutivas van a tener causa en la redacción de la Ley. En la medida en que los criterios de deslinde competencial no se encuentran suficientemente determinados, va a existir una zona de incertidumbre o zona gris en orden a concretar que autoridad de competencia es la competente para aplicar la LDC. De hecho parece que el propio legislador era consciente de que el empleo de conceptos que adolecen de un alto grado de indeterminación iba a ocasionar diversos conflictos en el futuro, especialmente, cuando las CCAA comenzarán a crear sus propias autoridades encargadas de velar por la defensa de la competencia y estas iniciaran la aplicación de la $\mathrm{LDC}^{34}$. Parece por estos motivos que el legislador optó por incluir en la Ley $1 / 2002$, en su artículo segundo, un sistema de resolución extrajudicial de conflictos con el fin de ir delimitando por el órgano encargado de resolver los mismo (Junta Consultiva) cuando determinadas conductas o prácticas restrictivas pueden ser consideradas de ámbito supraautonómico o afecten al conjunto del mercado nacional, en cuyo caso será el Estado el que acciones su competencia ejecutiva, o cuando son de ámbito infraautonómico desplegando su acción para conocer de las mismas las $\mathrm{CCAA}^{35}$.

No se trata de estudiar con detalle el sistema de resolución de conflictos creado por la Ley 1/2002 que excedería de nuestro ámbito de análisis, sino de

${ }^{33}$ En parecidos términos se expresa Arzoz, X., quien advierte que la «titularidad estatal de competencias ejecutivas no depende de criterios precisos, objetivos y previsibles, sino de conceptos jurídico indeterminados, de criterios finalistas (intereses supaautonómi$\cos$ ) o, dada la adopción de un criterio rígido de territorialidad, de la mayor o menor voluntad de apreciar efectos, más o menos directos, en más de una Comunidad Autónoma», vid., «Alternativas a la solución judicial de los conflictos competenciales en materia de defensa de la competencia», $R A P$, núm. 164, pág. 47.

${ }^{34}$ Da la sensación que o bien el legislador se limitó a transcribir o, empleando términos de Derecho comunitario, a transponer la STC 208/1999, o bien debido al ámbito fundamentalmente económico sobre el que despliega su acción la defensa de la competencia no supo o no pudo concretar mejor los puntos de conexión en orden a determinar con la debida claridad y precisión cuando debía entrar a conocer el Estado o cuando las CCAA la aplicación de la LDC.

35 Téngase en cuenta sobre este unto la ya examinada STC 71/2012, de 16 de abril. 
examinar la naturaleza jurídica de los conflictos que pueden ocasionarse derivados de la falta de concreción en el establecimiento de los puntos de conexión. En principio, una vez fijados los criterios de deslinde competencial y, de este modo, concretado que ente territorial puede activar su competencia ejecutiva en defensa de la competencia, es de suponer que la cuestión litigiosa que pueda surgir sea de naturaleza eminentemente aplicativa, centrándose sobre cuestiones de hecho que deben ser resueltas con carácter previo a la aplicación de la norma atributiva de la competencia (por ejemplo, la dimensión del mercado afectado, los efectos sobre los consumidores, etc. ${ }^{36}$. Por lo tanto la cuestión conflictiva que será objeto de discusión entre las partes no debería radicar sobre la titularidad de la competencia, sino sobre la determinación del hecho que determinará el ejercicio de aquella. De ello se deduce que un conflicto acerca de la interpretación de cómo deben aplicarse los puntos de conexión establecidos en la Ley 1/2002 no constituirá un conflicto de competencias de naturaleza constitucional, por lo que las partes no podrían plantear un conflicto de competencias ante el TC. De tal modo que en el caso de que no se resuelva el conflicto mediante los mecanismos previstos en el art. 2 de la Ley 1/2002, la vía pertinente para resolver el mismo será la jurisdicción contencioso-administrativa ${ }^{37}$.

No obstante, a pesar de lo señalado, ello no significa como señala X. Arzoz que se excluyan de forma tajante las controversias competenciales entendidas estas en sentido constitucional. Esto se debe esencialmente a que debido a la indeterminación de los criterios empleados por el legislador para la atribución del ejercicio de la competencia, pueden surgir dudas acerca de la propia titularidad de la misma. Así, por ejemplo, cuando el Estado pretenda ejercitar su competencia ejecutiva para conocer de una conducta que pueda afectar a la unidad de mercado (art. 1.2.b) Ley 1/2002), puede alzarse la oposición de alguna $\mathrm{CA}$ que se considere en un principio competente en virtud de los criterios

36 Vid., Arzoz, X., «Alternativas a la...», cit., pág. 48.

${ }^{37}$ La distinción entre controversias competenciales y controversias sobre cuestiones de hecho tiene su raiz en la STC 88/1989, de 11 de mayo (caso ATINA). En esta sentencia el TC distinguió entre un conflicto sobre el alcance territorial de una competencia autonómica y un conflicto acerca de la dimensión territorial de un supuesto de hecho. El conocimiento de la primera cuestión corresponde al TC mientras que el segundo debe ser resuelto por la jurisdicción contencioso-administrativa. Sobre esta jurisprudencia, vid., MARTIN-Retortillo BAQUeR, L., «Justicia administrativa y Comunidades Autónomas», $R A P$, núm. 121, 1990, págs. 84 y ss.; GARCÍA RoCA, J., «Conflictos entre el Estado y las Comunidades Autónomas ante el Tribunal Supremo: la competencia diferenciada entre las jurisdicciones constitucional y contencioso-administrativa», RVAP, núm. 62, 2002, págs. 89 y ss.; Gómez Montoro, A. J., y CaAmaño Domínguez, F., «De nuevo sobre quién debe resolver los conflictos territoriales de competencia», REDA, núm. 99, 1998, págs. 369 y ss. 
establecidos en el art. 1.3 de la Ley 1/2002. De igual modo, podría el Estado invocar el criterio de la territorialidad para reclamar el ejercicio de la competencia ejecutiva, mientras que la CA podría plantear no ya la existencia de que una determinada conducta tenga o no una dimensión supraautonómica, cuestión más o menos fáctica y sujeta a verificación y prueba, sino la propia definición del alcance territorial de sus competencia ejecutivas en defensa de la competencia, cuestión de naturaleza constitucional ${ }^{38}$. Esta posibilidad de que se puedan plantear conflictos de competencia de naturaleza constitucional ya viene prevista en la Ley 1/2002, cuando señala en su art. 2.1 in fine que emitido el informe (por cierto, de naturaleza no vinculante) de la Junta Consultiva, órgano encargado de resolver el hipotético conflicto, se podrá iniciar el procedimiento por el órgano que se considere competente «sin perjuicio de la aplicación de lo establecido en el capítulo II del Título IV de la Ley Orgánica 2/1979, de 3 de octubre, del Tribunal Constitucional».

Estas posibilidades alternativas que nos depara la Ley 1/2002, en el supuesto de que no se resuelva el conflicto, esto es, bien la vía jurisdiccional contencioso-administrativa, bien la vía constitucional no puede ser considerada como un mecanismo eficaz en la defensa de la competencia. En este ámbito se precisa cierta celeridad por parte de la Administración a la hora de resolver los procedimientos de defensa de la competencia, pudiéndose ocasionar graves perjuicios para las empresas y, por ende, para el correcto funcionamiento del mercado la dilación de los procesos debido a la aparición de conflictos sobre qué administración es la competente para entrar a conocer de una determinada conducta que presuntamente vulnere la LDC. El legislador debería haber tenido en cuentas estas consideraciones y haber establecido con una mayor claridad y precisión los puntos de conexión necesarios para determinar qué ente territorial puede accionar su competencia ejecutiva.

3.3. Ámbitos de la ejecución del Derecho de la competencia de exclusiva competencia del Estado

En virtud de lo expuesto resulta evidente que existen una serie de actuaciones que quedan retenidas en poder del Estado por constituir elementos que sí afectan al interés general del mercado nacional. De forma expresa como pretendiendo reafirmar aquellos supuestos de defensa de la competencia que deben ser de competencia del Estado, pero que podrían ocasionar dudas en su interpretación, como así ha ocurrido en el trámite parlamentario, en donde se cuestionaba la exclusión del conocimiento por parte de las Comunidades Autónomas de los temas relacionados con el control de concentraciones, la Ley $1 / 2002$ ha querido zanjar la cuestión y en su art. 1 apartado 5 establece de forma taxativa lo siguiente:

${ }^{38}$ Vid., ARzoz, X., «Alternativas a la...», cit., pág. 49. 
«Corresponderá en todo caso al Estado:

a) La aplicación de las normas contenidas en el capítulo II y en el capítulo III del Título I de la Ley 16/1989, de 17 de julio, de Defensa de la Competencia.

b) La autorización, mediante reglamentos de exención, de categorías de acuerdos, decisiones, recomendaciones, prácticas concertadas o conscientemente paralelas a que se refiere el artículo 5 de la Ley 16/1989, de 17 de julio, de Defensa de la Competencia.

c) La representación en materia de defensa de la competencia ante otras autoridades nacionales, Foros y Organismos Internacionales y, en concreto ante la Unión Europea, la OCDE, la OMC y la UNCTAD.

d) La aplicación en España de los artículos 81.1 y 82 del Tratado de la Comunidad Europea y su Derecho derivado, de acuerdo con los dispuesto al respecto en el artículo 25.c) de la Ley de Defensa de la Competencia ${ }^{39} \gg$.

En primer lugar son atribuidos a la exclusiva competencia de los órganos estatales de competencia los aspectos relacionados con las concentraciones y ayudas públicas, así como los reglamentos de exención.

Respecto al caso de las concentraciones empresariales parecía lógico, puesto que, en definitiva, se trata de un aspecto de defensa de la competencia que debería dentro de la órbita del mercado nacional, si bien ha ocasionado cierta conflictividad competencial con las CCAA como tendré ocasión de examinar en el apartado siguiente. Además en este ámbito la aprobación mediante normas de los denominados reglamentos de exención por categorías implica el ejercicio de la competencia legislativa del Estado en defensa de la competencia. Por otro lado, el tema de las ayudas públicas presenta una vertiente más problemática sobre la que no podemos detenernos en exceso en este punto. Valga destacar dos aspectos a tener en cuenta sobre las mismas que hace justificable la decisión adoptada por el legislador estatal: en primer lugar, en las ayudas públicas, además del control que puedan ejercer en su caso las autoridades europeas desde el momento en que constituyen un factor que puede extenderse más allá del ámbito territorial del Estado, no existe duda de que son un elemento que queda incorporado a todas las actividades de la empresa, de este modo se proyecta en todos sus ámbitos de actuación ${ }^{40}$.

${ }^{39}$ En la actualidad, recuérdese que tras la entrada en vigor del Tratado de Lisboa, las referencias a los arts. 81 y 82 del TCE deben hacerse a los arts. 101 y 102 TFUE.

40 Sobre el régimen jurídico de las ayudas estatales, vid.,FERnÁNDEZ FARrERES, G., El régimen de las ayudas estatales en la Comunidad Europea, Cuadernos de Estudios Europeos, Civitas-Fundación Universidad Empresa, Madrid 1993, págs. 129 y ss.; GARCÍATreVijano GarniCA, E., Los procedimientos comunitarios de control de ayudas de Estado, Cuadernos Civitas, Madrid 2002, págs. 24 y ss. 
Este hecho hace que el perceptor de la ayuda se encuentre en todo momento bajo sospecha, pues no existirá una actuación empresarial que no quede afecta de uno u otro modo por la ayuda; actuación que normalmente tendrá un ámbito territorial supraautonómico. En segundo lugar, es cierto que normalmente las ayudas suelen ser otorgadas por las Administraciones más cercanas a los sujetos perceptores de las mismas. Ello hace que los intereses locales puedan suponer una afectación del mercado nacional, por lo que se estima pertinente que se ponga una prudente distancia entre el que otorga la ayuda y el que la recibe, lo que justifica que sean los órganos estatales los competentes para dilucidar estos aspectos ${ }^{41}$.

En segundo lugar, la representación internacional del Estado en materia de defensa de la competencia resulta algo obvio, pues se entronca con el título competencial establecido en la cláusula $3^{\mathrm{a}}$ del art. 149.1 CE que atribuye al Estado la competencia exclusiva en materia de relaciones internacionales.

Por otro lado, en lo que se refiere a la aplicación en nuestro país de los arts. 101 y 102 TFUE, esta había sido atribuida por el Reglamento 1/2003 a las autoridades nacionales - CNMC-, así como la jurisdicción contenciosoadministrativa competente para controlar la actividad de éstos (todo ello sin perjuicio de la posible aplicación directa de las normas de defensa de la competencia por parte de la jurisdicción civil -jueces mercantiles- en los conflictos inter privatos). La exigencia de garantizar un mínimo de seguridad jurídica a los operadores económicos, así como la interpretación uniforme del Derecho Comunitario en España hace que sea del todo oportuno esta referencia expresa en la Ley 1/2002, como fue puesto de manifiesto en una enmienda introducida por el Grupo Parlamentario Popular, cuya justificación era la de «aclarar que la aplicación en España de la normativa comunitaria sobre conductas contrarias a la competencia, es una competencia, en todo caso, estatal ${ }^{42}$.

No obstante, el ejercicio por parte del Estado de las competencias referidas a la aplicación en España de la normativa de Derecho Comunitario en la defensa de la competencia, puede suscitar alguna duda respecto a la posible inconstitucionalidad de este precepto. Como es bien conocido la ejecución

${ }^{41}$ En este sentido afirma ARzoz que la «actividad de supervisión de las ayudas públicas otorgadas por lo poderes públicos, que encaja en la materia de defensa de la competencia en la medida en que las ayudas públicas ponen barreras u obstáculos financieros a la libre competencia, tiene que ver sin duda con la configuración de un mercado único y, en general, con el principio de unidad económica, y además no admite su fraccionamiento en una pluralidad de entes supervisores», de este modo «una supervisión de la incidencia de las ayudas otorgadas por el conjunto de los poderes públicos sólo tiene sentido con carácter unitario», cfr., «Comunidades Autónomas, puntos de...», cit., pág. 58.

${ }^{42}$ Enmienda núm. 61, BOCG, Serie A, núm. 40-11, de 8 de noviembre de 2001. 
interna de las normas comunitarias no implica una alteración del orden de distribución competencial por lo que la respuesta sobre a quién corresponde la aplicación de este Derecho de defensa de la competencia deberá ser resuelta de igual modo conforme a las reglas internas de reparto de competencias, ya que no existe un título competencial atributivo de la competencia específica de ejecución del Derecho Comunitario ${ }^{43}$. Por este motivo resulta necesario atender a la distribución competencial que opera nuestro bloque de constitucionalidad respecto a la defensa de la competencia en el sentido establecido por la STC 208/1999.

De acuerdo con este pronunciamiento jurisprudencial las competencias ejecutivas sobre este ámbito corresponden a las CCAA, si bien en aquellos supuestos en que la conducta anticompetitiva altere o pueda alterar el comercio supraautonómico o el conjunto del mercado nacional será el Estado el que tenga la competencia de ejecución con la finalidad fundamental de salvaguardar la unidad de mercado, competencia que encuentra su razón de ser en el art. 149.1.13 . En base a este precepto y, por ello, a la necesidad de aplicar de forma uniforme el Derecho Comunitario de la competencia en nuestro país de tal modo que no se produzca una aplicación desigual del mismo que pueda conducir a una quiebra de la ordenación general de la economía y de la unidad de mercado es por lo que la atribución de esta competencia de ejecución del Derecho Comunitario es efectuada a favor del Estado por el art. 5.d) de la Ley $1 / 2002$, por lo que este artículo no adolece, en mi opinión, de signos de inconstitucionalidad.

\subsection{El problema del control de concentraciones de empresas: ¿posible invasión del ámbito competencial de las Comunidades autónomas?}

Como acaba de examinarse, la Ley 1/2002 atribuyó la competencia sobre el procedimiento para el control de concentraciones económicas con la obligación de notificación previa al Estado. De este modo, todas aquellas operaciones de concentración empresarial en las que las sociedades afectadas superen los umbrales, que vienen determinados en atención al volumen de negocio y cuota de mercado de las mismas, de acuerdo con lo previsto en la LDC (2007) han de notificarse a la autoridad de competencia del Estado, esto es la $\mathrm{CNC}$, debiendo suspenderse su ejecución hasta que la misma dictamine sobre su autorización o no.

Como apunta F. MARCOS, la propia STC 208/1999 que ya ha sido examinada en profundidad, no hizo ningún pronunciamiento expreso sobre este ámbito del Derecho de la Competencia, lo que pudo influir en el legislador estatal al

${ }^{43}$ Sobre la ejecución del Derecho Comunitario, cfr., El control y la ejecución del Derecho Comunitario, MAP, Madrid 1998, págs. 83 y ss. 
contemplar en la Ley 1/2002, la competencia exclusiva del Estado en este ámbito material del Derecho de la Competencia ${ }^{44}$. Este hecho hizo que algunas Comunidades autónomas se mostraran críticas con esta opción empleada por la Ley $1 / 2002$, señalando que algunas operaciones de control de concentraciones podían tener una incidencia muy relevante en el ámbito autonómico lo que podía justificar la intervención de las autoridades autonómicas en el procedimiento de autorización de control de concentraciones empresariales ${ }^{45}$.

Así, algunas CCAA, inicialmente, no establecieron en su legislación de competencia, referencias a esta materia, si bien hubo otras que sí que contemplaron la posible intervención de las autoridades autonómicas de competencia como interesadas en el procedimiento de control de concentraciones que pudiera desarrollarse ante la CNC. Así, el art. 3.2.b) de la Ley 6/2004, de 12 de julio, reguladora de los órganos de defensa de la competencia de la Comunidad Autónoma de Galicia, preveía una competencia de naturaleza consultiva y de emisión de informe en «los procedimientos de las operaciones de concentración económica regulados en la Ley de Defensa de la Competencia cuando así lo solicite el tribunal de Defensa de la Competencia de la Administración General del Estado» ${ }^{46}$. Del mismo modo, la legislación gallega reconocía la capacidad de recabar información para enviar al Estado en este tipo de procedimientos, así como la facultad de personarse en los procedimientos de control de concentraciones ante la CNC cuando la operación afecte a empresas ubicadas o con establecimientos abiertos en la Comunidad gallega $^{47}$.

44 Vid., «Competencias autonómicas en los procesos de concentración de empresas», In Dret, Barcelona, octubre de 2001, págs.. 18 y ss.

${ }^{45}$ En este sentido, FRANCO señaló críticamente que la Ley 1/2002 no aprovechase «todas las potencialidades que representan los órganos de defensa de la competencia para que las autoridades autonómicas ejerciesen funciones en materia de control de concentraciones», vid., «La nueva Ley de Defensa de la Competencia y los órganos autonómicos», Gaceta Jurídica de la Competencia, núm. 248, págs. 97 y ss. Igualmente, CRUCELEGUI advierte que «no se puede obviar que algunas operaciones de concentración tienen una incidencia muy relevante (a veces exclusiva) en el ámbito territorial de una sola Comunidad autónoma. En consecuencia, hubiera sido conveniente prever mecanismos de colaboración (o delegación) con los órganos autonómicos de competencia en el análisis de operaciones de concentración de ámbito autonómico», vid., "Los modelos de aplicación descentralizada del Derecho de la Competencia en la UE y en el Estado español», Cuadernos Europeos de Deusto, vol. 38, págs. 104 y ss.

${ }^{46}$ De forma similar la Comunidad de Aragón recogió las competencias sobre control de concentraciones empresariales de manera análoga a Galicia, en su art. 3.d), e) y F) del Decreto 29/2006, de 24 de enero, del Gobierno de Aragón por el que se crean y regulan los órganos de defensa de la competencia en Aragón.

${ }^{47}$ La nueva Ley gallega 1/2001, de 8 de marzo de 2011, desaparece la posibilidad de personarse en los procedimientos de control de concentraciones ante la CNC, si bien se 
Igualmente, la LDC se hizo eco de estas preocupaciones y en su nueva redacción del año 2007 estableció una mínima intervención de las Comunidades Autónomas en aquellas operaciones de control de concentraciones que sean objeto de examen detallado, en segunda fase del procedimiento, al que pasan por entenderse que pueden obstaculizar la competencia en el merca$\mathrm{do}^{48}$. Así, su art. 58.1 señalaba en su segundo párrafo que «en el supuesto de que la concentración incida de forma significativa en el territorio de una Comunidad autónoma, la Dirección de Investigación solicitará informe preceptivo, no vinculante, a la Comunidad Autónoma afectada, a la que remitirá junto con la nota sucinta, copia de la notificación presentada, una vez resueltos los aspectos confidenciales de la misma, para emitir el informe en plazo de veinte días».

Sin embargo, justo con anterioridad a la reforma recogida en la LDC, ya se habían alzado diversas voces críticas de algunas Comunidades autónomas por la exclusión prácticamente total de su competencia en este ámbito material del Derecho de la Competencia. El argumento principal, teniendo en cuenta, la jurisprudencia vertida por el TC en su STC 208/1999, consistía en que si las operaciones de concentración podían afectar de forma principal a un ámbito territorial exclusivamente autonómico, la competencia debería corresponder a las CCAA. En este sentido, se recogió en la reforma del Estatuto de Autonomía de Cataluña de 2006 en el que se recoge expresamente este argumento al disponer su art. 154 que en sus apartados 1 y 2 señala:

«1. Corresponde a la Generalitat la competencia exclusiva en materia de promoción de la competencia en los mercados respecto de las actividades económicas que se ejercen principalmente en Cataluña.

2. Corresponde a la Generalitat la competencia ejecutiva en materia de defensa de la competencia en el ejercicio de las actividades económicas que alteren o puedan alterar la libre competencia en el mercado en un

prevé, dentro de lo que califica como funciones de colaboración y coordinación, la colaboración con la CNC en el control de concentraciones previsto en la LDC mediante el envío de la información que la CNC le solicite y la emisión de informe a solicitud de la CNC en aplicación de lo dispuesto en el art. 58.1 de la LDC.

${ }^{48} \mathrm{La}$ LDC ha sido objeto de recurso de inconstitucionalidad por el Consejo de Gobierno de Canarias, el 1 de abril de 2008, contra los arts. 9 y 13 de la misma, puesto que al regular el procedimiento de control de concentraciones, se ignora las competencias de las CCAA respecto de aquellas operaciones que se produzcan en el mercado geográfico canario. De este modo, la Comunidad Canaria estima que la reserva de competencia exclusiva a la $\mathrm{CNC}$ en esta materia infringe la competencia de las CCAA respecto de aquellas transacciones que se produzcan en el ámbito territorial insular como mercado geográfico definido. Sobre este particular, vid., F. Marcos, «Competencias autonómicas...», op. Cit., págs.. 31 y ss. 
ámbito que supere el territorio de Cataluña. Esta competencia incluye en todo caso:

a) La ejecución en medidas relativas a los procesos económicos que afecten a la competencia.

b) La inspección y ejecución del procedimiento sancionador. cial».

c) La defensa de la competencia en el ejercicio de la actividad comer-

Si bien no aparece recogida de forma expresa la competencia autonómica sobre el control de concentraciones empresariales, quedaba claro que el propósito del apartado 2 letra a) iba encaminado en esa dirección. Así, lo entendió el Estado que presentó recurso de inconstitucionalidad contra diversos preceptos de la Ley Orgánica 6/2006, de 19 de julio, que reformaba el Estatuto de Autonomía de Cataluña, entre los que se encontraba el citado precepto. El TC en su STC 31/2010, de 28 de junio, estimó que

«definida en los términos antes expuestos el alcance de la competencia asumida por la Comunidad autónoma, esto es, limitada territorialmente al ámbito autonómico, así como a las actuaciones restrictivas de la competencia en el mismo y de acuerdo, en todo caso, con la legislación estatal, no existe en principio razón alguna (...) para que la Comunidad Autónoma no pueda asumir competencias estrictamente ejecutivas en relación con aquellas concentraciones siempre que resulten incluidas en el ámbito de la competencia autonómica y carezcan de trascendencia supracomunitaria».

De esta manera el TC consideró que no se existen argumentos para desgajar el control de concentraciones empresariales del resto de las funciones de ejecución que desarrollan las autoridades de competencia, de tal modo que cuando se refieran a operaciones que limiten sus efectos al ámbito intraautonómico y no afecten al conjunto del mercado podrán ser competencia de las autoridades de competencia autonómicas.

La legislación autonómica aprobada con posterioridad a este pronunciamiento del TC, así como tras la aprobación de la nueva LDC, ha recogido las competencias autonómicas en este ámbito. Así, por ejemplo, la Ley 1/2009, de 12 de febrero, de la Autoridad Catalana de la Competencia, recoge en su art. 2.3 su competencia exclusiva sobre las «actividades económicas que se ejercen principalmente en Cataluña y que alteran o pueden alterar la competencia, en los términos establecidos por el artículo 154.1 y 2 del Estatuto», recogiendo en su art. 10.2.b) entre las funciones del Tribunal Catalán de Defensa de la Competencia las de «ejercer las funciones que la legislación de competencia atribuye al órgano colegiado en materia de concentraciones empresariales». En parecidos términos recoge esta función la Ley 1/2012, de 12 de febrero, de la Autoridad Vasca de Competencia, que en su art. 3.7 establece entre las competencias de dicha autoridad la de ejercer «las funciones que la legislación de defensa de la competencia le atribuye en materia de 
concentraciones empresariales y cualesquiera otras competencias que pudiera asumir de conformidad con la normativa vigente en materia de promoción y defensa de la competencia».

Para finalizar este apartado, conviene señalar que a pesar de las previsiones de las normas autonómicas de defensa de la competencia en materia de concentraciones empresariales, reconociendo de forma expresa la competencia de las autoridades autonómicas en el ámbito de las concentraciones empresariales de cuyos efectos no trasciendan del territorio autonómico, la virtualidad de estas previsiones sigue siendo de un alcance limitado. En primer lugar, porque la gran parte de las operaciones de concentración conllevan actividades de empresas que desarrollan sus actuaciones en un plano supraautonómico lo que conlleva que la competencia sea de la CNMC.

A estos efectos, conviene recordar como hace F. MARCos que el sistema de control de concentraciones previsto en la legislación española emplea dos elementos o umbrales diferentes, que operan de forma alternativa, para identificar aquellas alteraciones de la estructura de mercado que puede implicar distorsiones en el mantenimiento de una competencia efectiva en el merca$\mathrm{do}^{49}$. Sólo deben notificarse a las autoridades de competencia las operaciones en las que las empresas que participan en la transacción superan ciertos umbrales en su volumen de negocios o exceden de una cuota de mercado determinada. De este modo, como se prevé en la LDC se mantiene el umbral de la cuota de mercado para la notificación obligatoria de aquellas operaciones de concentración empresarial en las que, como consecuencia de las mismas, se adquiera o se incremente una cuota igual o superior al 30 por ciento del mercado relevante del producto o servicios afectados (art. 8.1.a) LDC). Este es el criterio que de manera principal establece y podría habilitar la existencia de concentraciones de relevancia exclusivamente autonómica, puesto que en la medida que el ámbito geográfico del mercado relevante pueda ser autonómico o infraautonómico, cabría la posibilidad de enervar la competencia de las autoridades autonómicas sobre estas operaciones de concentración empresarial. Sin embargo, tras la reciente reforma de la LDC por la Ley $2 / 2011$, de 4 de marzo, de Economía Sostenible (LES), se limita ostensiblemente la posibilidad de actuación de las autoridades de competencia autonómicas en el control de concentraciones, puesto que se exige un volumen de negocios mínimo adicional a la cuota de mercado para la aplicación del umbral del art. 8.1.a) LDC. En este sentido, la Disposición Final Tercera de la LES que modifica el citado precepto dispone lo siguiente:

49 Vid., «Competencias autonómicas en...», op. cit., págs. 35 y ss. Igualmente, sobre la interpretación y alcance del art. 8.1.a) LDC, vid., Folguera CRESPO, J., y VIDAL MARTINEZ, P., «Artículo 8», en Comentario a la Ley de Defensa de la Competencia, CivitasThomsonreuters, Madrid 2012, págs. 375 y ss. 
"Quedan exentas del procedimiento de control todas aquellas concentraciones económicas en las que, aun cumpliendo lo establecido en la letra a), el volumen de negocios global en España de la sociedad adquirida o de los activos adquiridos en el último ejercicio contable no supere la cantidad de 10 millones de euros, siempre y cuando las participes no tengan cuota individual o conjunta igual o superior al 50 por ciento en cualquiera de los mercados afectados, en el ámbito nacional o en un mercado geográfico definido dentro del mismo» ${ }^{50}$.

\section{5. Ámbitos del Derecho de la Competencia de competencia de las comunidades autónomas}

Tal y como ha quedado delimitada la competencia estatal parecía innecesario definir la competencia de las Comunidades Autónomas que sería la que en ejecución de la LDC, no correspondiese al Estado, conforme a los criterios señalados. Sin embargo, la Ley 1/2002 ha creído necesario delimitar la competencia de estos entes territoriales.

Recordemos que la STC 208/1999 delimitó la competencia de las Comunidades Autónomas empleando para ello dos criterios concurrentes. El primero se refería al lugar donde deben llevarse a cabo las actuaciones administrativas; el segundo se refería al lugar donde se cometan las conductas infractoras. De esta forma, según el pronunciamiento jurisprudencial, una Comunidad Autónoma ostentará competencia siempre que 1) las actuaciones ejecutivas hayan de realizarse en su territorio, y no afecten al mercado nacional, y 2) cuando se trate de actos realizados dentro del territorio de la Comunidad Autónoma y a su vez carezcan de trascendencia sobre el mercado supraautonómico.

La Ley 1/2002 en el apartado tercero del art. 1 parece haber acogido tan sólo el segundo criterio, esto es, el relativo a las conductas, al señalar que

"Corresponderá a las Comunidades Autónomas con competencias en la materia el ejercicio en su territorio de las competencias reconocidas en la Ley 16/1989, de 17 de julio, de Defensa de la Competencia respecto de los procedimientos que tengan por objetos las conductas previstas en los artículos 1, 6 y 7 de la mencionada Ley, cuando las citadas conductas, sin afectar a un ámbito superior al de una Comunidad Autónoma o al conjunto del mercado nacional, alteren o puedan alterar la libre competencia en el ámbito de la respectiva Comunidad Autónoma» ${ }^{51}$

50 Sobre este punto, vid., NAVARro, E., «Artículo 55. Notificación de concentración económica», en comentarios a la Ley de defensa de la Competencia», Civitas-Thomson Reuters, 2013, págs.. 913 y ss.

${ }^{51}$ Así, por ejemplo, en la Resolución del TCDC de 10 de marzo de 2004 que resolvía un recurso de alzada contra la Resolución de 25 de noviembre de 2003 de la Dirección General de Defensa de la Competencia de la Generalitat de Catalnya, en la que se acordaba el 
Podría pensarse en qué ocurriría, si por ejemplo, una posible conducta abusiva con efecto sobre una única Comunidad Autónoma realizada por una empresa cuya sede social se encuentre en otra Comunidad. En este supuesto hipotético, las actuaciones administrativas, desde las simples notificaciones hasta la ejecución de las sanciones, pasando por las inspecciones, habrán de realizarse en distinta Comunidad Autónoma. Por lo que el interrogante gira en torno si habría que trasladar la competencia a la $\mathrm{CNC}$, por considerar que se trata de un ámbito supraautonómico, o, por el contrario, se podría mantener la competencia autonómica por afectar la conducta a sólo una Comunidad Autónoma. Parece claro que en estos supuestos en que los efectos de la conducta anticompetitiva se produjeran en el ámbito exclusivo de una CA la competencia para conocer de la misma sería de esta, sin que pudiera alegarse que el ámbito supraautonómico sobre el que puedan desplegarse alguna de las actuaciones autonómicas sea justificación necesaria para entender que la competencia ejecutiva deba trasladarse a los órganos estatales. Todo ello, sin perjuicio, de que en ocasiones sean necesarios acudir a los principios de colaboración y de auxilio mutuo, regulados en los arts. 4 y ss. LPC y en el art. 4 de la Ley $1 / 2002$, con el fin de poder ejercitar plenamente la competencia autonómica ${ }^{52}$; así como los previstos en el art. 15 LDC que establece la coordinación de la CNC con los órganos competentes de las CCAA:

«1. La coordinación de la Comisión Nacional de la Competencia con los órganos competentes de las Comunidades autónomas se llevará a cabo

archivo de la denuncia formulada en su día contra el Colegi de Detectius Privats de Catalunya, se planteó por los recurrentes la posible incompetencia de la Dirección General de Defensa de la Competencia de la Generalitat al entender que las conductas (se referían al cobro por parte del Colegio Profesional de la habilitación temporal a los detectives no residentes en Cataluña, al cobro del visado colegial de documentos profesionales e incluso a la obligatoriedad de colegiación) eran susceptibles de afectar a un ámbito supraautonómico vulnerando de este modo lo dispuesto en el art. 1.1 de la Ley 1/2002. El TCDC señaló que las conductas denunciadas se realizan en el ámbito territorial de Cataluña, y es en «ese ámbito donde se podría alterar de forma esencial la libre competencia». Por lo tanto, «el mercado geográfico donde se podrían materializar las conductas denunciadas que, en ningún caso, y por la misma naturaleza de las actividades del Colegio, inciden en un ámbito superior al de Catalunya, ya que el Colegio no tiene capacidad de actuación más allá de este ámbito territorial», cuestión por cierto que fue reconocida por el SDC estatal mediante el envío de la nota sucinta en cumplimiento del art. 2 de la Ley 1/2002.

${ }_{52} \mathrm{El}$ art. 4 de la Ley 1/2002 relativo a los aspectos institucionales de la ejecución por parte de las Comunidades Autónomas de la LDC dispone: «1. El Servicio de Defensa de la Competencia y el Tribunal de Defensa de la Competencia podrán celebrar convenios de colaboración con los órganos competentes de las Comunidades Autónomas para la instrucción y resolución de los procedimientos que tengan por objeto conductas que sean tanto competencia del Estado como de estas últimas. Dichos convenios establecerán las formas y mecanismos concretos a través de los cuales se instrumentará la referida colaboración». 
según lo dispuesto en la Ley 1/2002, de 21 de febrero de coordinación de las competencias del Estado y las Comunidades autónomas en materia de Defensa de la Competencia.

2. A los efectos de facilitar la cooperación con los órganos jurisdiccionales y la coordinación con los órganos reguladores, la Comisión Nacional de la Competencia y los órganos de defensa de la competencia de las Comunidades Autónomas habilitarán los mecanismos de información y comunicación de actuaciones, solicitudes e informes previstos en los articulos 16 y 17 de la presente Ley respecto de aquellos procedimientos que hayan sido iniciados formalmente según lo previsto en la Ley 1/2002, de 21 de febrero de coordinación de las competencias del Estado y las Comunidades autónomas en materia de Defensa de la Competencia».

\subsubsection{La actividad de defensa de la competencia}

De acuerdo con lo previsto en la LDC así como en la Ley 1/2002 las autoridades de competencia autonómicas tienen competencia, en función de lo dispuesto por su normativa de creación, para la instrucción y resolución de los procedimientos sancionadores sobre aquellas conductas prohibidas por los arts. 1, 2 y 3 de la LDC que afecten a la competencia en el ámbito autonómico y que no excedan de él o afecten al conjunto del mercado nacional. Así, se prevé en las distintas leyes autonómicas de creación de las nuevas autoridades de defensa de la competencia como, por ejemplo, la Ley 1/2012, de 2 de febrero de la Autoridad Vasca de Competencia, dispone en su art. 3 lo siguiente:

«La autoridad vasca de la competencia incoará, instruirá y resolverá procedimientos sancionadores que tengan por objeto conductas restrictivas de la competencia, tales como conductas colusorias, abuso de posición dominante y falseamiento de la libre competencia por actos desleales que afectan al interés público, tal como se regula en la normativa de defensa de la competencia. En el ejercicio de dicha competencia la autoridad vasca de la competencia podrá:

a) imponer multas sancionadoras por vulneración de la legislación de defensa de la competencia,

b) imponer multas coercitivas respecto de las obligaciones establecidas en sus resoluciones, así como por incumplimiento del deber de colaboración,

c) adoptar medidas cautelares y de ejecución forzosa,

d) eximir del pago de multas o reducir sus importes, realizar inspecciones a empresas y asociaciones de empresas»

Estas competencias, como ya se ha señalado, no sólo pueden ejecutarse respecto de los procedimientos sancionadores sobre conductas que distorsionen la competencia siempre que no afecten a un ámbito territorial superior a 
las respectiva CA, sino que además las competencias autonómicas en este particular, deben desplegarse sobre conductas anticompetitivas que tengan una relevancia mínima, esto es, que afecten de forma significativa al interés público que se protege: el orden público económico. De este modo, las autoridades autonómicas podrán aplicar con cierto margen de discrecionalidad la regla de minimis prevista en el art. 5 de la LDC que establece que «las prohibiciones recogidas en los artículos 1 a 3 (...) no se aplicarán a aquellas conductas que, por su escasa importancia, no sean capaces de afectar de manera significativa a la competencia».

Finalmente, aunque será objeto de examen ulterior, debe señalarse que a los efectos de garantizar una aplicación uniforme de la LDC, se establece la posibilidad de que la DI comparezca como interesada en los procedimientos sancionadores incoados por las autoridades autonómicas de competencia e incluso la posibilidad de que el Consejo de la CNC pueda recurrir aquellos actos de las autoridades autonómicas que pongan fin al procedimiento sancionador ${ }^{53}$.

\subsubsection{La actividad de promoción de la competencia}

La actividad administrativa desplegada por las autoridades de competencia se ha centrado, tradicionalmente, en la persecución de las conductas ilícitas desde la perspectiva antitrust. Así, por un lado, ha ejercido la potestad sancionadora frente a los acuerdos o conductas restrictivas de la competencia e, igualmente, frente a los denominados abusos de posición de dominio. Por otro lado, se ha desarrollado del mismo modo una actividad de control frente a las estructuras de mercado a través del análisis y estudio de las concentraciones económicas, pudiendo éstas ser autorizadas, con o sin condiciones, o, por el contrario, ser denegadas su implementación.

Frente a esta modalidad de intervención administrativa ex post, en los sistemas modernos de competencia se ha ido progresivamente incluyendo entre sus formas de actuación administrativa las políticas de carácter proactivo denominadas de promoción de la competencia o advocacy -en términos anglosajones-. Se trata de políticas encaminadas a la persuasión, esto es, a

${ }^{53}$ Como señala MArcos, F., op. cit., pág. 14, «desde hace algún tiempo la DI se persona con regularidad como interesada en los procedimientos sancionadores incoados por las autoridades autonómicas». De igual forma, el Consejo de la CNC ha impugnado en vía jurisdiccional dos resoluciones adoptadas por las autoridades autonómicas: la Resolución de la Agencia de Defensa de la Competencia de Andalucía de 10 de noviembre de 2010 (S/11/2010, Compañias Aseguradoras de Córdoba), y la Resolución del tribunal de Defensa de la Competencia de la Comunidad de Madrid de 22 de diciembre de 2010 (2/2010, Centros Sociosanitarios): 
evitar problemas de competencia en los mercados, en lugar de perseguirlos. Por lo tanto, obedecen a una intención claramente de control ex ante, con una finalidad de regulación de aquellos mercados que adolecen de problemas de competencia, con independencia de los factores que contribuyen a la creación de esas disfuncionalidades anticompetitivas que pueden tener su origen en la propia regulación pública (por ejemplo, en la regulación de los contratos públicos), o puede ser de origen en conductas privadas de los distintos operadores en el mercado ${ }^{54}$.

Por estas razones, debe advertirse desde un primer momento que la actividad de promoción de la competencia se dirige principalmente a impedir que normas de naturaleza regulatoria o de cualquier otro tipo puedan crear ineficiencias en los mercados o puedan amparar restricciones en los mismos.

\section{A) Delimitación de la actividad de promoción de la competencia}

El concepto de promoción de la competencia o advocacy ha sido definido por contraposición a la actividad de limitación -enforcement- que habitualmente ha sido ejercida por las autoridades de competencia. En este sentido, se ha definido la competition advocacy como «todas aquellas actividades llevadas a cabo por las autoridades de competencia que no se corresponden con la categoría de las actividades administrativas de policía» (International Competition Network)

De este modo, la actividad administrativa de promoción de la competencia comprende tanto las actividades encaminadas a «convencer» a las diversas Administraciones Públicas para que se abstengan de adoptar medidas innecesariamente anticompetitivas, como aquellos otros esfuerzos dirigidos a intentar acercar la política de competencia a los diversos operadores económicos que actúan en los mercados, así como a los consumidores y usuarios.

Junto a esta vertiente convencional de la actividad de promoción de la competencia, fundamentalmente sustentada en la consulta o revisión de la regulación por parte de las autoridades de competencia, se ha ido extendiendo y consolidando una interpretación más amplia de esta modalidad de actuación administrativa abriéndose también a la promoción del conocimiento jurídico y económico del Derecho de la Competencia.

${ }^{54}$ Sobre la actividad de advocacy, vid., RodRíGuez Míguez, J.A., «Promoción versus defensa de la competencia en España, una visión de conjunto», Dereito, vol. 19, núm. 2, 2010, págs. 52 y ss.; P. AvILA, «El papel de la Comisión Nacional de Competencia en la actividad de regulación de las Administraciones Públicas», en Derecho de la Competencia y regulación en la actividad de las Administraciones Públicas, (Dir. J. Guillén Caramés), Civitas-Thomson Reuters, Madrid 2011, págs. 375 y ss.; SAla ArQuER, J.M., «Artículos 25 y 26», en Comentario a la Ley de Defensa de la Competencia, Civitas-Thomson Reuters, Madrid 2010, págs. 621 y ss. 
Las nuevas normas autonómicas de creación de autoridades de competencia han dado una gran importancia a esta forma de actividad administrativa de clara tendencia reguladora de los mercados, pues se configura como un instrumento de política económica que contribuye, por una parte, al correcto funcionamiento de los mercados y, en consecuencia, al dinamismo y la competitividad de la economía, y, por otra, a la defensa del interés general, concretado en los intereses de los consumidores y usuarios. Fiel reflejo de esta nueva forma de desarrollo de una política proactiva de la competencia lo constituye la Ley 1/2012, de 2 de febrero, de la Autoridad Vasca de la Competencia, que establece en su art. 3.3 entre las competencias de esta institución las de:

"promover la competencia en los mercados ejerciendo las siguientes funciones:

a) Promover y realizar estudios y trabajos de investigación en materia de competencia,

b) Realizar informes generales sobre sectores, con propuestas que ayuden a corregir o mejorar una competencia efectiva,

c) Realizar informes sobre la actuación del sector público,

d) Realizar informes sobre el impacto de las ayudas públicas sobre la competencia efectiva en los mercados,

e) Dirigir a las administraciones públicas propuestas conducentes al mantenimiento o restablecimiento de la competencia en los mercados,

f) Proponer al consejero o consejera competente en materia de política económica y defensa de la competencia, para la elevación, en su caso, al Consejo de Gobierno, las directrices de política de defensa de la competencia en el marco de la política económica de aquél o aquélla y, en particular, las propuestas de elaboración y reforma normativa correspondientes»

Finalmente, se ha incluido dentro de la actividad de promoción, la posibilidad de que las autoridades autonómicas de competencia puedan impugnar ante la jurisdicción competente los actos sujetos al Derecho Administrativo y las disposiciones generales de rango inferior a la ley, cuando de ellos se deriven obstáculos al mantenimiento de una competencia efectiva en los mercados. Esta potestad de impugnación se encuentra originariamente prevista en el art. 13.2 LDC que dice expresamente:

«Sin perjuicio de las competencias de la Comisión Nacional de la Competencia, los órganos competentes de las Comunidades Autónomas están legitimados para impugnar ante la jurisdicción competente actos de las Administraciones Públicas autonómicas o locales de su territorio sujetos a Derecho administrativo y disposiciones generales de rango inferior 
a la ley de los que se deriven obstáculos al mantenimiento de una competencia efectiva en los mercados $»^{55}$.

Este nuevo instrumento del que pueden servirse las autoridades autonómicas de la competencia puede revestir una cierta relevancia respecto a la eliminación de determinadas trabas y barreras que las Administraciones Públicas -autonómicas y locales- pueden establecer contra la libre competencia en los mercados ${ }^{56}$.

\section{B) Encuadre jurídico de la actividad de promoción: el empleo del soft law en el Derecho de la competencia}

En general, este tipo de actuaciones que pueden desarrollar las autoridades de competencia, se encuentran dirigidas a promover la competencia efectiva en los mercados y, en consecuencia, a regular directa o indirectamente los mismos. Este claro componente regulador se identifica con los denominados instrumentos de soft law empleados habitualmente por la Comisión Europea en el ámbito del desarrollo de la política de competencia europea, con la finalidad de

${ }^{55}$ Esta previsión ha sido trasladada a las normas autonómicas de competencia, por ejemplo, art. 3.4 de la Ley 1/2012 de la autoridad vasca de la competencia; o el art. Art. 14 de la Ley 1/2011 reguladora del Consejo Gallego de la Competencia.

${ }^{56}$ Hasta la fecha las CCAA no han hecho uso de esta potestad de impugnación. Sí, la ha empleado en varias ocasiones la CNC, en virtud del art. 12.3 LDC, habiendo hasta la fecha dos pronunciamientos judiciales. En primer lugar, tenemos la sentencia del tribunal Superior de Justicia de la Comunidad valenciana de 22 de octubre de 2012 en el que la CNC impugnaba el Decreto 24/2010, de 29 de enero del Consell, relativo al Plan de Modernización de las concesiones de transporte público regular permanente de viajeros por carretera, al considerar que el plazo establecido para la prórroga de las concesiones era contrario a la legislación comunitaria en esta materia constituyendo una clara obstrucción de la libre competencia. El Tribunal estimó el recurso de la CNC señalando que el Decreto valenciano era claramente contrario a la legislación comunitaria y que, por tanto, el mantenimiento de esta norma dentro del ordenamiento jurídico produciría un efecto perverso en sede de competencia que no cuenta con el aval del Derecho europeo ni del Derecho estatal. La segunda sentencia proviene del Tribunal Superior de Justicia de Galicia de 24 de mayo de 2012, en que la CNC había impugnado la Resolución de 22 de junio de 2010 de la Consellería de Medio Ambiente, territorio e Infraestructuras por la que se inadmitió por falta de legitimación el requerimiento formulado por la $\mathrm{CNC}$ para que declarase la nulidad de pleno derecho de la Resolución de 26 de febrero de 2010 de la Dirección General de Movilidad por la que se aprobó el Plan de modernización de las concesiones de transporte público regular permanente de personas de uso general por carretera de Galicia. En este asunto, el Tribunal desestimó el recurso de la CNC por falta de legitimación de la misma. Sobre este punto, vid., GuILLÉN CARAMÉs, J., «La impugnación por las autoridades de competencia de las actuaciones de las Administraciones Públicas restrictivas del Derecho de la Competencia», en Derecho de la Competencia y regulación en la actividad de las Administraciones Públicas, Civitas-Thomson Reuters, Madrid 2011, págs.. 441 y ss. 
incidir en el comportamiento de los operadores en el mercado, así como de dirigir indirectamente sus conductas en los mismos.

En la Unión Europea (en adelante UE) se identifican este tipo de técnicas de cierta naturaleza normativa, con los denominados actos atípicos de carácter no vinculante establecidos en el TFUE: recomendaciones y dictámenes. La importancia de este tipo de instrumentos ha sido reconocida tanto por la doctrina jurídica como por la jurisprudencia del Tribunal de Justicia de la $\mathrm{UE}^{57}$.

Por lo tanto, el empleo de este tipo de instrumentos de soft law, resulta de gran importancia en el desarrollo de una política de competencia pro activa por parte de las autoridades administrativas.

La primera nota destacable acerca de los actos de soft law producidos por las autoridades de competencia es que se caracterizan por su falta de adecuación a ninguna tipología clásica de normas, ni tampoco se requiere un procedimiento específico para la producción de los mismos.

Junto a esta nota de ausencia de formalidad en la aprobación de este tipo de instrumentos de tanta importancia en el Derecho de la Competencia, la segunda característica esencial de los mismos es la ausencia de efectos jurídicos vinculantes, si bien ello no quiere decir que carezcan de efectos jurídicos, como más adelante se examinará, lo que puede tener una incidencia en el desarrollo de esta actividad por parte de las autoridades autonómicas de la competencia.

En general, pueden destacarse los siguientes caracteres esenciales de los instrumentos de soft law en el Derecho de la Competencia:

a) Son normas jurídicas dirigidas a una pluralidad de destinatarios, que carecen de efectos obligatorios, ni poseen procedimientos formales y reglados de elaboración ${ }^{58}$.

b) No pueden emplearse como parámetro de enjuiciamiento de disposiciones generales, ni tampoco de actos administrativos.

c) No son susceptibles de impugnación directa ante la jurisdicción contencioso-administrativa.

${ }^{57}$ Sobre este punto, vid., Alonso García, R., «El soft law comunitario», RAP, núm. 154, 2001, págs. 63 y ss.

${ }_{58}$ Si bien la Disposición Adicional Tercera de la LDC dispone: «La Comisión Nacional de la Competencia podrá publicar Comunicaciones aclarando los principios que guían su actuación en aplicación de la presente Ley. En particular, las Comunicaciones referentes a los artículos 1 a 3 de esta Ley se publicarán oído el Consejo de Defensa de la Competencia». Por lo que aunque no se establece un procedimiento concreto, deberá escucharse la opinión del Consejo de Defensa de la Competencia, que se configura como el único elemento reglado en el proceso de elaboración de este tipo de normas de soft law, como son las Comunicaciones interpretativas. 
d) Su principal carácter se encuentra en el ámbito de la interpretación jurídica, dando sentido a las disposiciones generales del ordenamiento jurídico y coadyuvando a éstas en el proceso de enjuiciamiento de actos administrativos.

C) La regulación económica mediante las técnicas del soft law: sus efectos jurídicos. Límites a la actividad de promoción de la competencia autonómica

EL soft law tiene la virtualidad de producir efectos con una extensión que comprende tanto a los poderes públicos como a los particulares que operan en el mercado. Desde esta perspectiva, puede apuntarse una dualidad de ámbitos sobre los que este tipo de instrumentos despliegan una especial intensidad jurídica.

Por un lado, aquellos actos de soft law adoptados por las autoridades de competencia con la finalidad de constreñir su propia conducta y, así otorgar seguridad jurídica a quienes se relacionan jurídicamente con aquéllas (por ejemplo el tema de las Directrices de cuantificación de multas)

Por otro lado, puede tener efectos frente a los operadores económicos públicos o privados- desde el prisma de interpretación de las normas -legales o reglamentarias-. Se trata, en consecuencia de imponer una obligación o un deber a quien tiene la facultad de interpretar y aplicar el Derecho de la Competencia a que lo haga teniendo en cuenta el contenido del soft law aplicable a cada asunto del que se esté conociendo (STJUE Grimaldi, 322/88, de 13 de diciembre de 1989).

Dos puntos son relevantes a la hora de examinar los efectos que puede desplegar el soft law en la normativa de competencia. De un lado, las normas legales o reglamentarias - hard law- pueden contener determinaciones expresas en dónde se establezcan los efectos que debe desplegar el soft law. En este sentido, no suele ser el Derecho de la Competencia un sector en el que las normas legales o reglamentarias contengan este tipo de reenvío hacia el soft law, si bien la Disposición Adicional Tercera de la LDC parece establecer esta fórmula de reenvió al disponer que

«La Comisión Nacional de la Competencia podrá publicar Comunicaciones aclarando los principios que guían su actuación en aplicación de la presente Ley. En particular, las Comunicaciones referentes a los artículos 1 a 3 de esta Ley se publicarán oído el Consejo de Defensa de la Competencia».

En este sentido la $\mathrm{CNC}$ ha aprobados dos Comunicaciones al respecto: la Comunicación sobre cuantificación de sanciones en 2009, y la Comunicación sobre Terminación Convencional de Expedientes sancionadores en 2011, que constituyen dos normas de soft law cuya finalidad esencial es establecer 
unas directrices de carácter general que guíen la actuación sancionadora de la CNC y contribuyan a aumentar la seguridad jurídica de los operadores económicos que actúan en los mercados.

De otro lado, nos encontramos con la posibilidad de que el hard law no determine los efectos que debe tener el soft law, en cuyo caso hay que distinguir dos vertientes para determinar cuáles son los posibles efectos de este tipo de instrumentos ${ }^{59}$.

En primer lugar, puede señalarse una vertiente anulatoria, de tal manera que el soft law no constituye parámetro de enjuiciamiento de disposiciones generales ni tampoco de actos administrativos. Si bien, en este caso, si las autoridades de competencia se apartan de lo dispuesto en el soft law emanado por ellas, surge el deber de motivar dicha decisión, tal y como se deriva del art. 54.1.c) de la Ley 30/1992, de Régimen Jurídico de las administraciones Públicas y del Procedimiento administrativo Común (LPC). De este modo, por medio de la motivación se intenta garantizar la seguridad jurídica de los operadores económicos sujetos a las reglas de la competencia.

Pero junto a esta vertiente, puede apreciarse una segunda posibilidad que es la que podría denominarse vertiente interpretativa. En este caso, el soft law, no es una disposición aplicable en la resolución de conflictos en el ámbito del Derecho administrativo, si bien se configura como un deber de interpretación del hard law de conformidad con el soft law. Se trata, por tanto, de una manifestación de una voluntad reguladora por parte de las autoridades de competencia, si bien, manifestada al margen de los cauces formales de regulación. Al igual que en la vertiente anulatoria, se trata de garantizar la seguridad jurídica de las empresas que pueden dirigir sus conductas económicas en un sentido o en otro guiadas por las directrices emanadas de las autoridades de competencia. Puede señalarse, que las autoridades de competencia al aprobar y publicar (bien en boletines oficiales, bien en su propia página web) instrumentos de soft law, generan en los operadores económicos lo que podría denominarse una expectativa reguladora, en virtud de la cual, se marcan criterios y se completa el sentido e interpretación que deben darse a las normas del Derecho de la Competencia (hard law).

Por lo tanto, resulta evidente que la actuación normativa por parte de la $\mathrm{CNC}$ y las autoridades autonómicas de la competencia al aprobar soft law de naturaleza interpretativa de la LDC y sus normas de desarrollo puede generar en las empresas sujetas a la aplicación de la LDC, una creencia legítima de que un determinado proceder de la $\mathrm{CNC}$ de acuerdo con sus criterios de interpretación de la norma de hard law, de tal modo que puede y debe quedar vinculada la $\mathrm{CNC}$ por dicha actuación interpretativa, por lo que si empleara

59 Vid., al respecto, SARMIENTO, D., El soft law administrativo, Civitas-Thomson, Madrid 2008, págs. 162 y ss. 
una interpretación diferente y no debidamente motivada se podría afectar al principio de confianza legítima en el precedente administrativo quedando afectada de esta manera la seguridad jurídica de las empresas y pudiendo ser nula la actuación administrativa. Así, por ejemplo, la CNC ha empleado el principio de confianza legítima en la actuación previa de la autoridad de competencia en su Resolución de 14 de abril de $2010^{60}$, si bien opta por que en este caso no se encuentra afectado, al señalar lo siguiente:

"(...) el Consejo entiende que podían existir dudas razonables de que la medida regulatoria impuesta por el ACM de 2002, de limitar la duración de los nuevos contratos de adquisición de derechos audiovisuales de fútbol a tres años, pudiera ser interpretada por clubes y operadores no dominantes como un indicio de que duraciones superiores podían resultar incompatibles con el Derecho de la Competencia. No obstante, en la medida en que el Informe de fútbol de 11/6/2008 se pronuncia claramente sobre la limitación de los contratos de adquisición en exclusiva de estos derechos (...) y sobre la prohibición de los derechos de tanteo y retracto, la alegación de la confianza legítima en la actuación precedente de las autoridades de competencia (...) resulta notablemente debilitada, y claramente no puede prosperar desde la fecha en que la DI notifica a las partes el primer $\mathrm{PCH}(\ldots)$ »

Del mismo modo, es ilustrativa la sentencia del Tribunal Supremo de 4 de diciembre de 2009, en la que también se alegaba la vulneración de la confianza legítima por parte de la autoridad de competencia al interpretar soft law antitrust, en la que se resuelve que

"en el presente caso, si bien es cierta la existencia de dudas interpretativas sobre la aplicación del artículo 81 del Tratado a los contratos de suministro de combustibles y carburantes en exclusiva, amparados en estas fórmulas contractuales complejas, no podemos entender que la actuación de las compañias recurrentes se haya visto sorprendida por la actuación del tribunal de Defensa de la Competencia, que aflora en la Comunicación de 24 de diciembre de 1962, en que se adoptan criterios para determinar la naturaleza de la actuación que desarrollan agentes y comisionistas, desde la perspectiva de aplicación del anterior artículo 85 del Tratados, en las Decisiones de la Comisión de 23 de noviembre de 1973 y de 19 de diciembre de 1984 (...) y que por ello cabe calificar de predecible»

Finalmente, otro ejemplo que puede traerse a colación es la sentencia de la Audiencia Nacional de 6 de mayo de 1999, en el asunto Cartel de la Sidra en la que sostuvo que

${ }^{60}$ Expte. S/0006/07, AVS, Mediapro, Sogecable y Clubs de Fútbol de $1^{\circ} y 2^{\circ}$ División. 
«la aplicación de tal principio, puede implicar la ausencia de responsabilidad en el ámbito sancionador, cuando el administrado haya obrado guiado por la confianza que en la corrección de su actuar haya generado la Administración. Pero para que tal principio opere con toda su extensión, entendemos que es preciso que la Administración que con sus actos concluyentes genere la confianza, debe ser la Administración competente en la materia; pues no cabe que genere confianza quien con nitidez no es competente para ello».

En definitiva, la aprobación de soft law por parte de la autoridad de competencia, estatal o autonómica, puede generar un grado de certidumbre y creencia en el operador económico sujeto a la LDC a la hora de interpretar la legislación de competencia. Si bien, debe advertirse que el principio de confianza legítima se puede ver igualmente afectado no solo por las actuaciones o precedentes realizados por la autoridad de competencia, sino también por otras autoridades administrativas que carecen de competencia sobre del Derecho antitrust $t^{61}$.

De este modo, queda claro que el empleo del soft law tiene una clara intención reguladora produciendo claros efectos jurídicos ad extra que inciden de forma significativa en los diversos operadores económicos que actúan en los mercados. De este modo, las autoridades autonómicas deben ser cautelosas en el desarrollo de la actividad de promoción puesto que en numerosos casos los efectos jurídicos que pueden desplegarse sobre los sujetos económicos pueden trascender el ámbito territorial de una CA, así como afectar a la unidad de mercado que, como ya he señalado, constituyen límites al ejercicio de las competencias autonómicas en el Derecho de la Competencia.

${ }^{61}$ Así, por ejemplo, lo establece la sentencia del Tribunal Supremo de 23 de febrero de 2000, en el asunto $A N E L E$ señalando que «en el presente caso no cabe la menor duda de que esa recomendación hecha por ANELE a sus empresas editoras asociadas, venía dada por la que a ella le había realizado a su vez el Ministerio de Educación y Ciencia, como se infiere de la administra admonición de «la necesidad de que esas subidas fueran limitadas. Es decir, cumpliendo el deseo manifestado por la Administración, ANELE primero, y los editores después pusieron coto a la subida libre los precios en la legítima confianza de que actuaban de forma correcta. Sería absurdo sancionar una conducta que la propia Administración sancionadora aconsejaba».

Esta tesis ha sido criticada por J. COSTAS al advertir que, en su opinión, la respuesta correcta a la cuestión no puede ser otra más que, con carácter general, «sólo la actuación de la autoridad de competencia constituirá un signo externo lo suficientemente concluyente para generar legítimamente en la empresa confianza en la legalidad de su conducta anticompetitiva, que le exima de toda culpabilidad en el ámbito del Derecho sancionador de defensa de la competencia»., vid., «La confianza legítima en la actuación de las Administraciones Públicas como límite al Derecho de Defensa de la Competencia», en Derecho de la Competencia y..., op. cit., pág. 125. 
A ello puede añadirse que si las autoridades autonómicas de competencia a la hora de implementar la actividad de promoción de la competencia mediante la regulación de los mercados inciden, de forma directa o indirecta, en las conductas de los operadores privados o públicos -cuando éstos actúan en el mercado en régimen de Derecho privado- puede constituir un exceso competencial al incidir sobre el título competencial «legislación mercantil» que es competencia exclusiva del Estado, en virtud del art. 149.1.6 ${ }^{\mathrm{a}} \mathrm{CE}$.

TITTLE: The competences of the National Markets and Competition Commission and the Regional Authorities in the application of the Competition Law.

RESUMEN: Desde la STC 208/1999 que se limitaba parcamente a reconocer a las Comunidades Autónomas su competencia en la ejecución de la Ley de Defensa de Competencia, siempre y cuando no afecta a la unidad de mercado, ha proliferado toda una red autonómica de Autoridades de Competencia con una idiosincrasia propia. Tal complejo panorama requiere un sesudo y honesto análisis de los correspondientes títulos competenciales en materia de derecho de la competencia, analizando la aplicación del ámbito de las competencias exclusivas del Estado, de las competencias de ejecución de las CCAA, e incluso las posibles invasiones competenciales en materias como el problema del control de las concentraciones.

En el mismo orden de ideas, la vigencia de la Ley 15/2007 supuso un punto de inflexión en cuanto al paradigma organizativo de las autoridades de competencia, superando el modelo dual y avanzando hacia un modelo de organismo único. Ante tal avance las distintas CCAA tuvieron que reaccionar, bien adaptándose a los nuevos vientos, o incluso condenándose a su propio ostracismo. Las que sobreviven apuestan por fortalecer su independencia, y por lograr la necesaria integración en un organismo único de los cometidos de instrucción y resolución de expedientes. En tal sentido, no resultará baladi ahondar en la actividad especifica de las autoridades de competencia, que no solo compendian la instrucción y resolución de procedimientos sancionadores, sino también actividades propiamente de promoción merced a instrumentos propios del soft law.

Como cuadratura de todo esta compleja red de agentes guardianes de la defensa de la competencia, entrarán en escena criterios previstos por la Ley 1/2002 para delimitar cuando una conducta altera la libre competencia en un ámbito supraautonómico o en el conjunto del mercado nacional, entre otros la dimensión del mercado, la cuota de mercado, el alcance de la restricción, etc.

PALABRAS CLAVE: Títulos competenciales, exclusivas, compartidas, ejecución, autoridades, independencia, instrucción y resolución, Ley 15/2007.

ABSTRACT: From the STC 208/1999 that was limiting merely to recognizing to the Regional Communities their competence in the execution of the 
Law of Defense of Competition, as long as does not concern the unit of market, has proliferated the whole regional network of the Competition Authorities with an own idiosyncrasy. Such a complex panorama needs a brainy and honest analysis of the corresponding competence tittles as for law of the competence, analyzing the application of the area of the exclusive competences of the State, the competences of execution of the CCAA and even the possible competence invasions in matters as the problem of the control of the concentrations.

In the same order of ideas, the force of the Law 15/2007 supposed a point of inflexion as for the organizational paradigm of the Competition Authorities, overcoming the dual model and advancing towards a model of the unique organism. That such an advance provokes that CCAA had to react, well adapting to the new winds, or even being condemned to his own ostracism. Those who survive bet for strengthening its independence, and for achieving the necessary integration in the unique organism of the assignments of instruction and resolution of processes.

In this sense, mercy will not turn out to be paltry to analyze deeply the specific activity of the Competition Authorities, which not only summarize the instruction and resolution of sanctioning procedures, but also activities properly of promotion in light of the own instruments of the soft law.

As squaring of quite this agents' complex network guardians of the defense of competition, will enter scene criteria foreseen by the Law 1/2002 to delimit when a conduct alters the free competence in a supra autonomic or in the set of the domestic market, among others the dimension of the market, the market share, the scope of the restriction, etc.

KEY WORDS: Competence tittles, exclusives, shared, execution, authorities, independence, instruction and resolution, Law 15/2007.

RECIBIDO: 29.05.2015

ACEPTADO: 04.06.2015 
